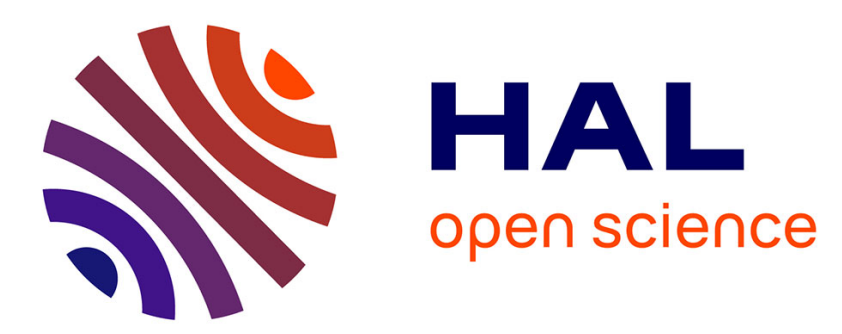

\title{
Energy absorption characteristics in hybrid composite materials for marine applications under impact loading: Case of tidal current turbine
}

Houda Laaouidi, Mostapha Tarfaoui, Mourad Nachtane, Mourad Trihi

\section{- To cite this version:}

Houda Laaouidi, Mostapha Tarfaoui, Mourad Nachtane, Mourad Trihi. Energy absorption characteristics in hybrid composite materials for marine applications under impact loading: Case of tidal current turbine. International Journal of Energy Research, 2021, 45, pp.5894 - 5911. 10.1002/er.6210 . hal-03166976

\section{HAL Id: hal-03166976 \\ https://hal.inrae.fr/hal-03166976}

Submitted on 13 Apr 2021

HAL is a multi-disciplinary open access archive for the deposit and dissemination of scientific research documents, whether they are published or not. The documents may come from teaching and research institutions in France or abroad, or from public or private research centers.
L'archive ouverte pluridisciplinaire HAL, est destinée au dépôt et à la diffusion de documents scientifiques de niveau recherche, publiés ou non, émanant des établissements d'enseignement et de recherche français ou étrangers, des laboratoires publics ou privés. 


\title{
Energy absorption characteristics in hybrid composite materials for marine applications under impact loading: Case of tidal current turbine
}

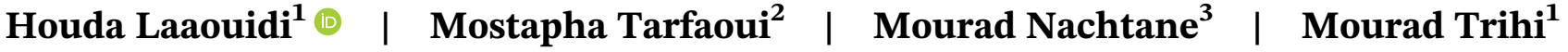

${ }^{1}$ FSAC-UH2C, Laboratory for Renewable Energy and Dynamic Systems,

Casablanca, Morocco

${ }^{2}$ ENSTA Bretagne, IRDL UMR CNRS 6027, Brest, France

${ }^{3}$ University of Bordeaux, CNRS, Arts et Metiers Institute of Technology, Bordeaux INP, INRAE, I2M Bordeaux, Bordeaux, France

\section{Correspondence}

Houda Laaouidi, FSAC-UH2C, Laboratory for Renewable Energy and Dynamic Systems, Casablanca, Morocco. Email: laaouidi.h@gmail.com

\begin{abstract}
Summary
The tidal current turbine is the most efficient way to extract energy from the sea. This system can be prone to critical loads such as impact accidental in the installation and maintenance phase. Indeed, several complex modes of damage susceptible to harming the stability of the structure are studied to conceive hybrid composite nozzles with better resistance to damage. For this reason, two scenarios of low-velocity impact of a hybrid composite nozzle (glass/ carbon) were investigated. In both cases, the impact was realized in the region of the trailing edge of the nozzle, and the results obtained were compared between three different laminated. On the other hand, damage modeling was formulated using the finite element method based on the Hashin criteria. Energy conservation of the nozzle was verified to validate the numerical model. Also, the effects of the impact velocity and the panel's flexibility on the initiation and propagation of damage have been studied. Depending on the results, the stacking sequence significantly influences the formation of damage. However, the results show that the hybrid nozzle with CGG (carbon/glass/glass) stacking has a higher impact resistance compared to other laminates.
\end{abstract}

\section{K E Y W O R D S}

contact/impact, damage mechanics, finite element method (FEM), hybrid fibers composites, marine operation, marine turbine

\section{1 | INTRODUCTION}

In recent years, renewable marine energy (RME) plays an important role in satisfying the increasing energy demand and to reduce the emission of greenhouse gases; it is becoming more and more appreciated, mainly due to its predictability. ${ }^{1}$ Indeed, the application of tidal turbines to exploit tidal currents can only be efficient if the hydrodynamic performance is predicted. Currently, this technology is under development as devices capable of converting the kinetic energy contained in flowing water into electrical power. In a recent study, some researchers ${ }^{2-4}$ cited companies that have started to establish tidal current turbine parks, such as Sabella in France, Andritz Hydro Hammerfest (AHH) in Anglesey (Wales, UK), MeyGen in Scotland, GE \& Alstom Energy (France), and DCNS, that will start work in the coming years. These projects represent a veritable response adapted to the needs of the industry. For example, the MeyGen project is currently the biggest tidal current development project in the world, and the largest group of multiturbine companies to start the development of this energy system. ${ }^{5}$ On the other hand, there is the FloTEC project, which was created in 2016 with funding from the European Union, which seeks to prove the potential of floating tidal systems to produce predictable, low-cost, reliable, and low-risk energy for the 
European electricity grid. To achieve these objectives, the SR200 turbine, regarded as the most powerful tidal turbine in the world, has been installed. ${ }^{6}$

Several types of turbines have been conceived, but the most commonly used are horizontal-axis turbines with two- or three-blade rotors able to extract a great quantity of energy from marine currents. ${ }^{7}$ Even though research on tidal turbines treats many different fields of interest, the most frequently studied subject is certainly power performance. $^{8}$

The ducted tidal turbine is subject to particular constraints because of the aggressive conditions that reign in the marine environment and maintenance and installation phase. In this context, composite materials occupy a crucial place in developing systems to convert marine renewable energy under severe environmental conditions. Due to their interesting properties, especially high stiffness, their lightness, and excellent corrosion resistance, they represent the perfect solution for structure developers. These conditions require the recourse to laminated composite materials like glass or carbon fiberreinforced polymer. Several studies have been conducted to evaluate the behavior of composites material exposed to impact. For example, Velasco et al indicate ${ }^{9}$ that damage inflicted on fiber-reinforced composite materials is characterized by progressive degradation of resistance and rigidity due to the formation of micrdamages in fiber and matrix. The damage is generally manifested as matrix cracking, the debonding between the fibers and matrix, and fiber breakage. Several researchers have performed different models of failure criteria to predict damage in composite laminates. ${ }^{10}$ For instance, $\mathrm{Xi} \mathrm{Li}$ et $\mathrm{al}^{11}$ investigated the applicability of failure criteria and damage evolution methods in finite element analysis of composite laminates subjected to low-velocity impact. On the other hand, modeling methods for damage using property degradation and residual strength models have been established by various authors. ${ }^{12-14}$

Recently, the control of the behavior of composite turbines has progressed enormously. Nachtane et $\mathrm{al}^{7}$ studied the effect of environmental impacts on the mechanical properties of a tidal turbine made of glass fiber-reinforced polymer composite. The results showed that damage was observed in different zones of the structure. Ullah et $\mathrm{al}^{15}$ analyzed the damage caused by impacts on tidal turbine blades. The composite materials used are composed of glass fiber-reinforced polymers. Furthermore, Tual et $\mathrm{al}^{16}$ analyzed the effects of seawater aging on composite materials for tidal turbine blades. The composite material employed in this study was carbon/epoxy.

According to the literature, several researchers have demonstrated that the fabrication of composites from a single reinforcing fiber is generally not adapted to particularly complex loading situations. ${ }^{17}$ For example, the carbon fibers have high tensile strength but are brittle to shear forces and thus have a low resistance due to lowspeed impact damage. ${ }^{18}$ According to Santhanam et al, ${ }^{19}$ composite materials made from a single reinforcing fiber tend to absorb moisture in a marine environment, which results in a weakening of the composite. To solve these problems, several studies have been conducted on hybrid fiber composites, adding ductile fibers like glass fibers, basalt, and aramid to carbon fiber-reinforced composite materials to increase their resistance to damage. Mahmoud $^{20}$ reported that higher impact performance could be observed by applying the same materials with different structures to form a hybrid laminate type. Sun et $\mathrm{al}^{21}$ have analyzed experimentally and by finite element method the mechanical properties of carbon/basalt composite materials; the results showed that the hybrid effect was positive for tensile and flexural strength. On the other hand, the current studies on hybrid composites are principally based on fiber alignment and ply stacking sequence. ${ }^{18}$ Only a few researchers have carried out studies on the effect of the stacking sequence on the tensile and flexural strength of hybrid composites. ${ }^{22,23}$ In these studies, it was found that placing a relatively stronger fiber on the outside of the composite increases the flexural strength. It was also reported that the tensile strength increased with increasing fiber volume in the hybrid composite. In this context, recourse to hybridization is an excellent method to improve the fracture resistance of composite materials, while keeping adequate mechanical performance for structural application.

The review of the literature indicates that no studies have been conducted in the past on the application of hybrid composites in ducted tidal turbines. In this context, this work aims to investigate the dynamic behavior and the mechanical response of a hybrid composite nozzle under accidental impact during maintenance and installation operations. The prediction of the induced damage on the structure during the impact has been studied by the finite element method by using the Abaqus software. Two different impact scenarios were considered, the impact was realized on the trailing edge zone of the nozzle and the simulated damage was analyzed for different materials.

\section{2 | STRUCTURAL ANALYSIS AND MATERIALS}

\section{1 | Structure}

The hydrodynamic profile of the ducted tidal turbine was determined using Heliciel software, Figure 1A. To analyze the mechanical behavior of the nozzle during a maintenance and installation operation, the numerical model is developed in Abaqus software using the finite 
FI G URE 1 Nozzle of the marine current turbine [Colour figure can be viewed at wileyonlinelibrary.com]
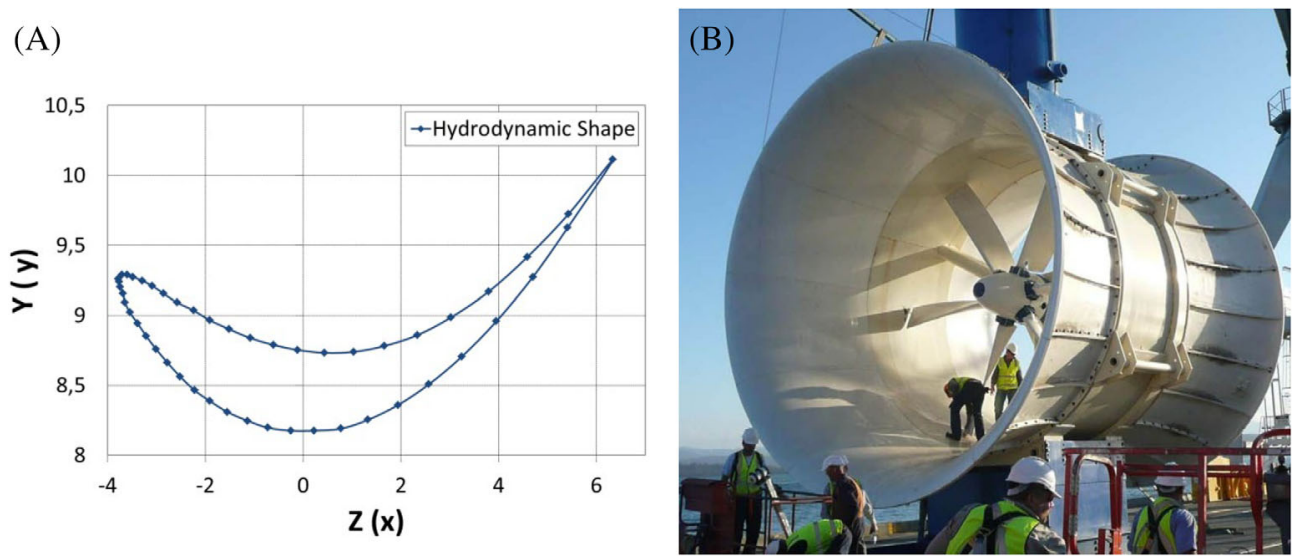

FI G URE 2 The stacking sequence configurations [Colour figure can be viewed at wileyonlinelibrary.com]
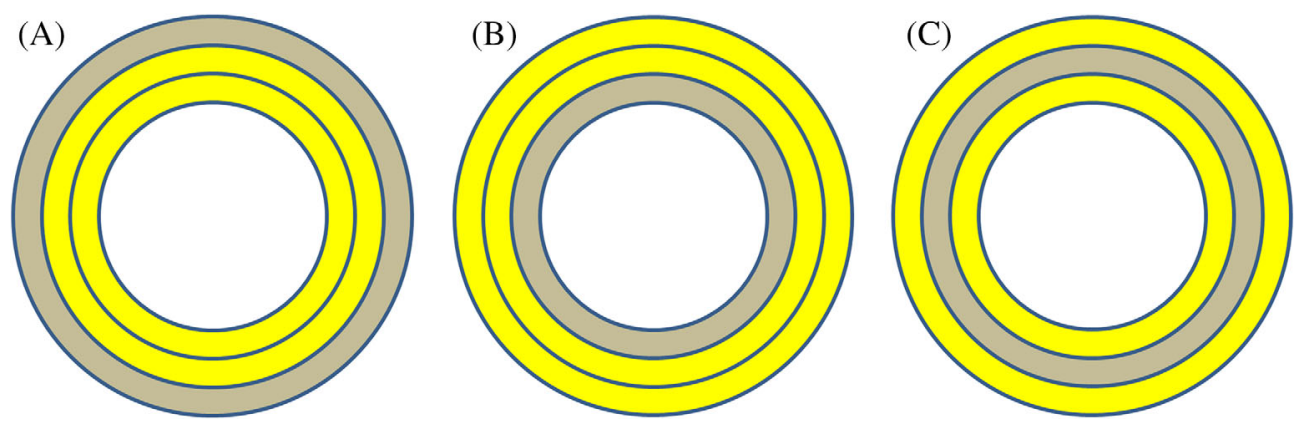

T A B L E 1 Properties of glass-epoxy ${ }^{24}$

\begin{tabular}{|ll|}
\hline Properties & Value \\
$\rho\left(\mathrm{kg} / \mathrm{m}^{3}\right)$ & 1659 \\
$E_{1}(\mathrm{MPa})$ & 26705 \\
$E_{2}(\mathrm{MPa})$ & 7495 \\
$\mathrm{Nu}_{12}$ & 0.28 \\
$G_{12}=G_{13}=G_{23}(\mathrm{MPa})$ & 2833 \\
$\mathrm{Xt}(\mathrm{MPa})$ & 1006 \\
$X_{\mathrm{c}}(\mathrm{MPa})$ & 487 \\
$Y_{\mathrm{t}}(\mathrm{MPa})$ & 46 \\
\hline$Y_{\mathrm{c}}(\mathrm{MPa})$ & 132 \\
\hline$S_{\mathrm{L}}(\mathrm{MPa})=S_{\mathrm{T}}(\mathrm{MPa})$ & 42 \\
\hline
\end{tabular}

element method (FEM). The total diameter of the nozzle is $20 \mathrm{~m}$, and its mass is about 16.99 tons. Figure 1B illustrates the 3D nozzle of the tidal current turbine.

\section{2 | Materials}

Tidal current turbines are generally exposed to accidental impacts during maintenance and installation operations. To respond to industrial needs, usually related to a mass gain problem, hybridization offers an excellent method for improving the fracture resistance of composite materials,
TABLE 2 Properties of carbon-epoxy ${ }^{24}$

\begin{tabular}{|ll|}
\hline Properties & Value \\
\hline$\rho\left(\mathrm{kg} / \mathrm{m}^{3}\right)$ & 1238 \\
\hline$E_{1}(\mathrm{MPa})$ & 1928 \\
\hline$E_{2}(\mathrm{MPa})$ & 4598 \\
$\mathrm{Nu}_{12}$ & 0.32 \\
\hline$G_{12}=G_{13}=G_{23}(\mathrm{MPa})$ & 1729 \\
$\mathrm{Xt}(\mathrm{MPa})$ & 1429 \\
$X_{\mathrm{c}}(\mathrm{MPa})$ & 530 \\
$Y_{\mathrm{t}}(\mathrm{MPa})$ & 41 \\
\hline$Y_{\mathrm{c}}(\mathrm{MPa})$ & 145 \\
\hline$S_{\mathrm{L}}(\mathrm{MPa})=S_{\mathrm{T}}(\mathrm{MPa})$ & 83.4 \\
\hline
\end{tabular}

while maintaining the adequate mechanical performance for marine renewable energy applications. The composite used in this study is a hybrid laminate submerged in epoxy resin with a thickness of $0.64 \mathrm{~mm}$ per layer. ${ }^{24}$ The configurations of the stacking sequence have been established in the following manner: glass/glass/carbon (GGC), carbon/ glass/glass (CGG), and glass/carbon/glass (GCG) extending from the internal surface to the external surface. The total thickness of the laminate is $9.6 \mathrm{~mm}$, and the composite structure layup is $(0 / 45 / 90 / 45 / 0)$, with $n=15$, Figure 2 . Tables 1 and 2 present the mechanical properties of the composites. 


\section{I IMPACT SCENARIOS AND BOUNDARY CONDITIONS}

The ducted tidal turbine is exposed to accidental impacts during installation and maintenance operations. Their installation necessitates the use of extremely powerful cranes or lifting systems, which are carried on service ships. The operations are risky in the open sea if the boat itself does not have considerable dimensions to remain stable against the waves during transhipment operations. In this case, two impact scenarios can occur. In the first case, the structure may be subject to impacts related to the components present in the vessel. In the second case, it can be impacted by different surfaces of the ship. In this context, two different impact scenarios were simulated:

- Case Fixed nozzle and mobile impactor, Figure 3A.

- Case Mobile nozzle and fixed impactor, Figure 3B.

In case 1 , a belt wrapped around part of the nozzle was chosen as boundary conditions. Figure $3 \mathrm{~A}$ shows the encased section and the impactor geometry. In case 2, the boundary condition of the "Encastre" type is applied in the impactor reference point, as represented in Figure 3B.

$$
\mathrm{U} 1=\mathrm{U} 2=\mathrm{U} 3=\mathrm{UR} 1=\mathrm{UR} 2=\mathrm{UR} 3=0
$$

In the two cases, the length of the impactor is $30 \mathrm{~m}$, its width is $1 \mathrm{~m}$, and its mass is about 1 ton.

For a better turbine conception and better analysis of its behavior under dynamic loads, the structure was exposed on its trailing edge to an accidental impact during maintenance and installation operations. A maintenance description of the system is depicted in Figure 4.

\section{4 | NUMERICAL MODEL}

The finite element modeling was developed in the Abaqus/ Explicit software to accurately predict and analyze the hybrid composite nozzle behavior, which is generally subjected to accidental impacts during maintenance operations. In this regard, the composite hybrid nozzle was modeled as a deformable structure and meshed with the shell quadrilateral S4R type element. On the other hand, the impactor is modeled as a rigid body. As mentioned in the previous section, two impact scenarios were modeled (Case 1 and Case 2). In case 1, the projectile weighs 1 ton, and its velocity was applied as an initial condition in its reference point which is equal to $4 \mathrm{~m} / \mathrm{s}$, while in case 2 , the
(A)<smiles>[Y]C([Y])[3H]</smiles>

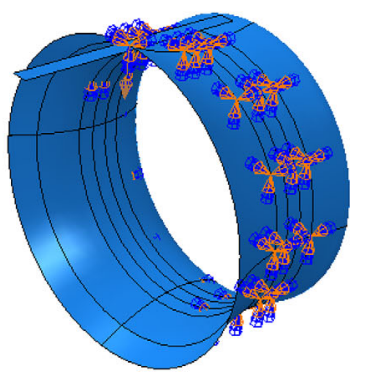

(B)
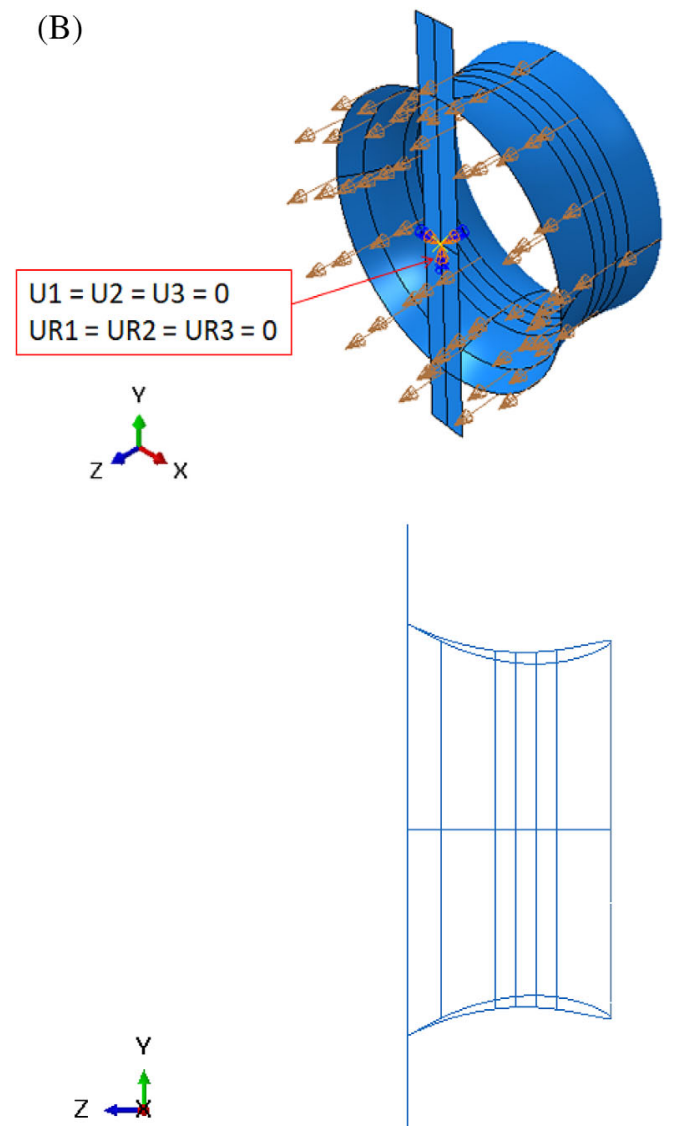

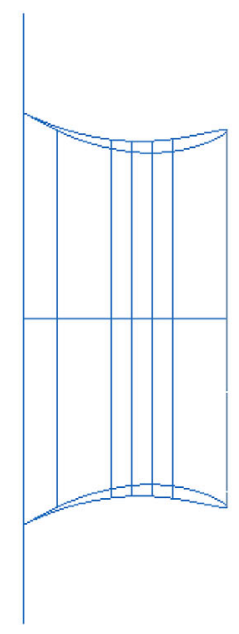

FIGURE 3 Impact scenarios [Colour figure can be viewed at wileyonlinelibrary.com] 


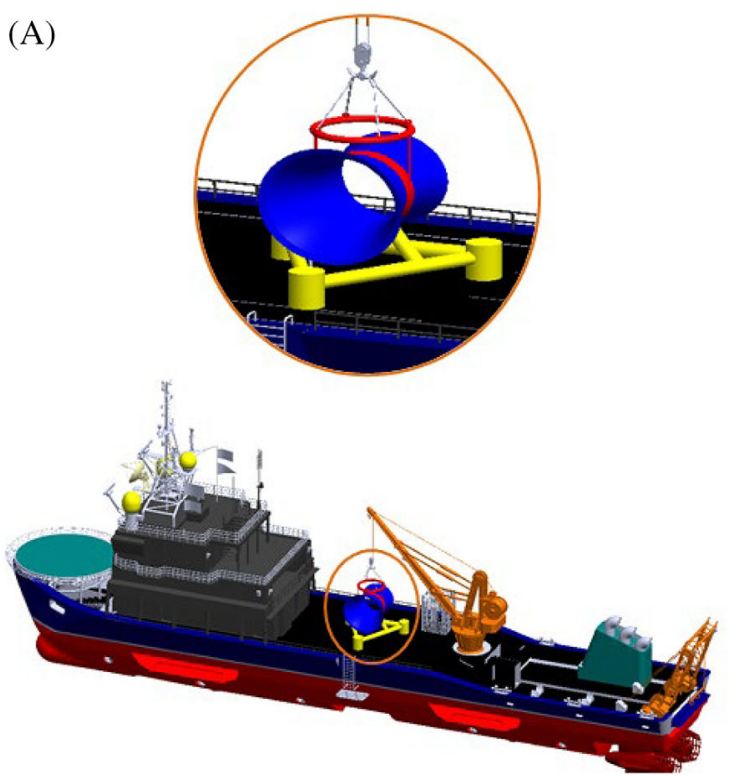

(B)

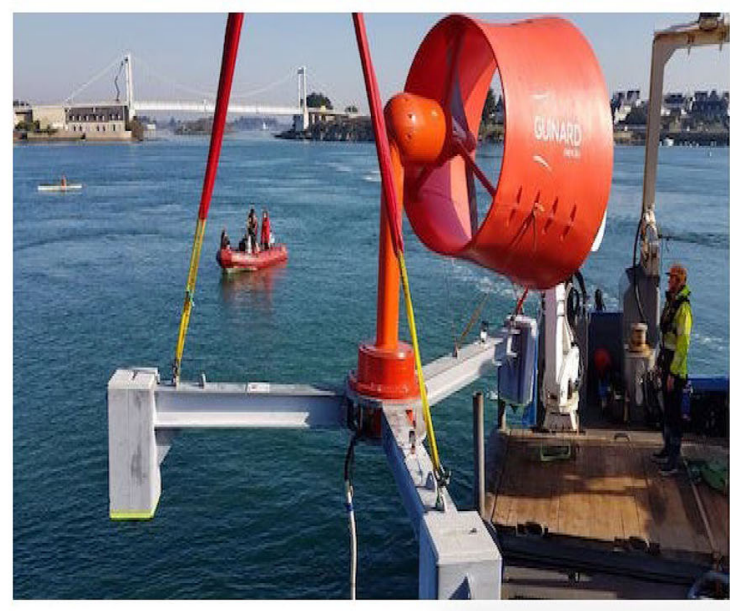

F I G U RE 4 Context description [Colour figure can be viewed at wileyonlinelibrary.com]

FIGURE 5 The final mesh of the numerical simulation [Colour figure can be viewed at wileyonlinelibrary.com]
(A)

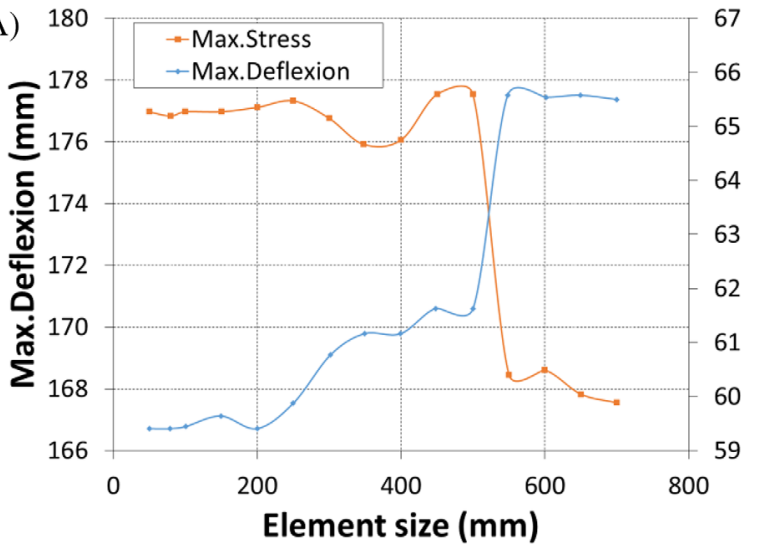

(B)

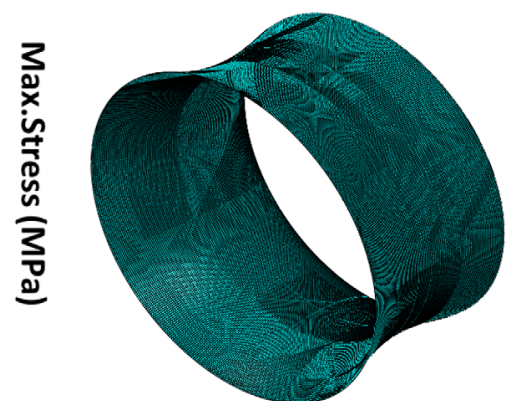

nozzle displaces at a speed of $4 \mathrm{~m} / \mathrm{s}$, and the impactor is fixed.

\section{1 | Mesh convergence}

A modeling strategy was conducted to reduce computation time and optimize the mesh model without affecting the accuracy of the simulation results. This strategy is based on identifying an optimal mesh by studying the convergence of the numerical model, as shown in Figure 5A.

The variation of maximum deflection and maximum stress vs the number of elements is illustrated in Figure 5A. The results of successive calculations seem to converge starting from 129490 elements with a mesh size of $100 \mathrm{~mm}$ length. The value of convergence is calculated from a ratio "mesh size/total size of the structure" of 0.005 . It can be seen from Figure $5 \mathrm{~A}$ that the more the mesh is refined, the maximum stress increases and the maximum displacement decreases. Indeed, it is not suitable to apply quadratic elements in nonlinear structural analyses to such modeling as it takes a lot of calculation time. For this particular reason, the choice in our study consists of using a four-node quadrilateral element with linear interpolation and reduced integration (S4R). This is known for its robustness suitable for large applications and allows better accuracy at a reduced cost by using a fine mesh instead of a coarse mesh. Figure 5B depicts the final mesh size of $100 \mathrm{~mm}$ used for the nozzle.

\section{2 | Damaged material response}

The impact at low speed reflects a case of quasistatic loading and represents a crucial industrial case for damage tolerance. These impacts can considerably decrease 
the residual strength of composite structures without necessarily make visible marks on the outer surface. Studies have shown that damage caused by this type of loading is similar to those resulting from a static indentation test. $^{25-27}$ Thus, indentation tests are currently commonly used for experimental studies of impacts on low-speed impacts.

In this part, the modeling of progressive damage is examined by introducing the formula of different failure modes. In composites materials, damage can be defined in two distinct phases in terms of damage initiation and damage progression. In this model, the constitutive equations for damaged composite materials ${ }^{28}$ are expressed in the form of:

$$
\hat{\sigma}=M \sigma
$$

where, $\sigma$ is the real stress. $M$ is the damage operator, having the diagonal form as shown in Table 3.

The shear damage is a way of identifying in the stack the plies in which the rupture of matrix and fibers occurs. Indeed, the damage variables $d_{f}, d_{m}$, and $d_{s}$ may have distinct compression and tension values, referenced by $d_{f}^{t}$, $d_{f}^{c}, d_{m}^{t}, d_{m}^{c}$ corresponding to four following modes:

$$
\begin{gathered}
d_{f}=\left\{\begin{array}{l}
d_{f}^{t} \text { if } \hat{\sigma}_{11} \geq 0 \\
d_{f}^{c} \text { if } \hat{\sigma}_{11}<0
\end{array}\right. \\
d_{m}=\left\{\begin{array}{l}
d_{m}^{t} \text { if } \hat{\sigma}_{22} \geq 0 \\
d_{m}^{c} \text { if } \hat{\sigma}_{22}<0
\end{array}\right.
\end{gathered}
$$

The corresponding stiffness matrix is determined from the equation below:

$c=\frac{1}{D}\left[\begin{array}{ccc}\left(1-d_{f}\right) E_{1} & \left(1-d_{f}\right)\left(1-d_{m}\right) \vartheta_{21} E_{1} & 0 \\ \left(1-d_{f}\right)\left(1-d_{m}\right) \vartheta_{12} E_{2} & \frac{1}{\left(1-d_{m}\right) E_{2}} & 0 \\ 0 & 0 & D\left(1-d_{s}\right) G_{12}\end{array}\right]$

with

$$
D=1-\left(1-d_{f}\right)\left(1-d_{m}\right) \vartheta_{12} \vartheta_{21}
$$

where, $D, E_{1}, E_{2}$, and $G_{12}$ are undamaged material moduli. $\vartheta_{12}, \vartheta_{21}$ are undamaged material Poisson's ratios.

\section{3 | Damage initiation criteria}

The approach to detect the failure by damage mechanics is complex and requires knowledge of specific failure parameters. An alternative to facilitate the analysis of the rupture consists of adopting rupture criteria. Fiber deterioration in compression and tension and matrix failure in compression and tension were defined by Hashin's as four failure criteria for composite materials. This criterion is implemented in the Abaqus Code. Thus, in our study, this criterion is adopted to treat the problem related to the reduction of the elastic properties of laminates and to evaluate their degradation.

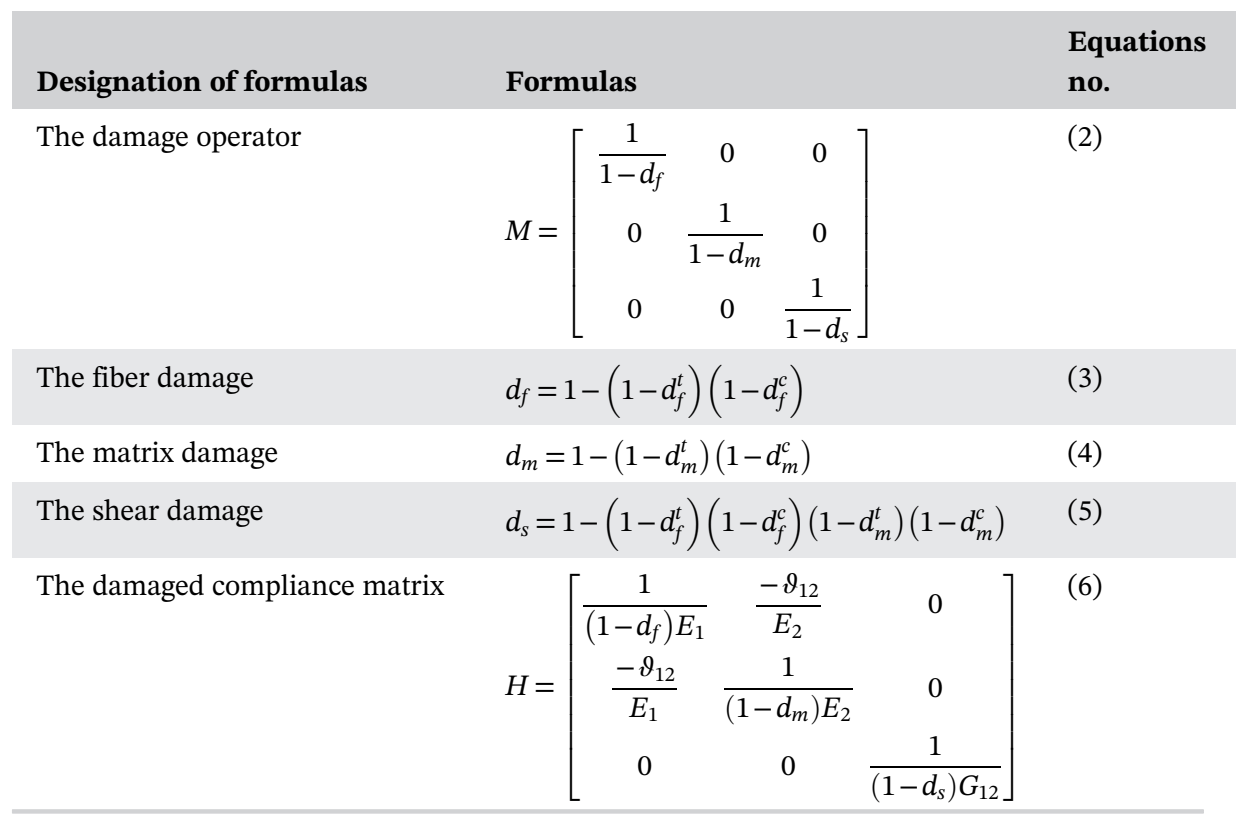

TA BLE 3 The constitutive equations of damaged composite laminates

$$
\begin{aligned}
& M=\left[\begin{array}{ccc}
\frac{1}{1-d_{f}} & 0 & 0 \\
0 & \frac{1}{1-d_{m}} & 0 \\
0 & 0 & \frac{1}{1-d_{s}}
\end{array}\right] \\
& d_{f}=1-\left(1-d_{f}\right)\left(1-d_{f}\right) \\
& H=\left[\begin{array}{ccc}
\frac{1}{\left(1-d_{f}\right) E_{1}} & \frac{-\vartheta_{12}}{E_{2}} & 0 \\
\frac{-\vartheta_{12}}{E_{1}} & \frac{1}{\left(1-d_{m}\right) E_{2}} & 0 \\
0 & 0 & \frac{1}{\left(1-d_{s}\right) G_{12}}
\end{array}\right]
\end{aligned}
$$

Designation of formula

Equations

(2) 
The initiation criteria are described as follows ${ }^{29}$ :

- Fiber tensile failure $\left(\hat{\sigma}_{11} \geq 0\right)$

$$
F_{f}^{t}=\left(\frac{\hat{\sigma}_{11}}{X^{T}}\right)^{2}+\alpha\left(\frac{\hat{\tau}_{12}}{S^{L}}\right)^{2}
$$

- Fiber compressive failure $\left(\hat{\sigma}_{11}<0\right)$

$$
F_{f}^{c}=\left(\frac{\hat{\sigma}_{11}}{X^{C}}\right)^{2}+\alpha\left(\frac{\hat{\tau}_{12}}{S^{L}}\right)^{2}
$$

- Matrix tensile failure $\left(\hat{\sigma}_{22} \geq 0\right)$

$$
F_{m}^{t}=\left(\frac{\hat{\sigma}_{22}}{\mathrm{Y}^{\mathrm{T}}}\right)^{2}+\left(\frac{\hat{\tau}_{12}}{\mathrm{~S}^{\mathrm{L}}}\right)^{2}
$$

- Matrix compressive failure $\left(\hat{\sigma}_{22}<0\right)$

$$
F_{m}^{c}=\left(\frac{\hat{\sigma}_{22}}{2 S^{T}}\right)^{2}+\left[\left(\frac{Y^{C}}{2 S^{T}}\right)^{2}-1\right] \frac{\hat{\sigma}_{22}}{Y^{C}}+\left(\frac{\hat{\tau}_{12}}{S^{L}}\right)^{2}
$$

$F_{f}^{t}, F_{f}^{c}, F_{m}^{t}$, and $F_{m}^{c}$ are the four modes of failure identified in Hashin criteria, the coefficient $\alpha$ represents the contribution of shear stress on fiber tensile, and $\hat{\sigma}_{11}, \hat{\sigma}_{22}$, $\hat{\tau}_{12}$, the stress tensor.

Where, $X^{T}, X^{C}$ : denote the tensile and the compressive strengths in the direction of the fibers. $Y^{T}, Y^{C}$ : denote the tensile and the compressive strengths in the transverse direction. $S^{L}, S^{T}$ : denote the longitudinal and the transverse shear strengths of the composite.

\section{4 | Damage evolution}

The material stiffness progressively deteriorates according to a variable $d$, when the damage initiation criterion has been achieved. The values of this variable vary from zero when the damage begins to one $(d=1)$ when complete failure has happened in the fiber or matrix element. ${ }^{30}$ The failure criterion is defined in terms of the energy release rates associated with the damage variables corresponding to the four failure modes. In the case of a linear softening process, the variable reflecting the evolution of damage for each mode $(i)$ is defined as follows ${ }^{31}$ :

$$
d=\frac{\delta_{i, \mathrm{eq}}^{f}\left(\delta_{i, \mathrm{eq}}-\delta_{i, \mathrm{eq}}^{0}\right)}{\delta_{i, \mathrm{eq}}\left(\delta_{i, \mathrm{eq}}^{f}-\delta_{i, \mathrm{eq}}^{0}\right)}
$$

In the softening part, the equivalent displacement of each mode $(i)$ satisfies:

$$
\delta_{i, \mathrm{eq}}^{0} \leq \delta_{i, \mathrm{eq}} \leq \delta_{i, \mathrm{eq}}^{f}
$$

The zone area controlling softening is given by:

$$
\delta_{i, \mathrm{eq}}^{f}-\delta_{i, \mathrm{eq}}^{0}=\frac{2 G_{i}}{\delta_{i, \mathrm{eq}}^{0}}
$$

where $G_{i}$ represents the energy dissipated during the propagation of the damage, $\delta_{i, \text { eq }}^{0}$ denotes the equivalent displacement, $\sigma_{i, \mathrm{eq}}^{0}$ indicates the equivalent initial stress, and $\delta_{i, \text { eq }}^{f}$ refers to the equivalent displacement inducing the deletion of the element.

\section{5 | RESULTS AND DISCUSSION}

The damage resulting from an accidental impact is capable of affecting the ability to perform the intended function, even when the area of apparent damage is very small. ${ }^{32-36}$ Indeed, taking into consideration the low manoeuvring speed during maintenance and installation operations, the impact behavior during a low-energy impact must be studied. Hybrid composite structures possess greater rigidity than metallic materials. Nevertheless, due to the stratification of their layers and the weakness of the interfaces, this makes them extremely sensitive to shocks. This damage to laminate is not easy to identify. The absence of comprehension of impact tolerance of tidal current turbine systems is a major issue that prevents further use. It is essential to assess and predict the damage resulting from an accidental low-velocity impact to enhance the integrity and safety of hybrid composite structures in the maritime environment.

As mentioned in the preceding sections, two impact scenarios were investigated in the trailing edge zone of the nozzle during the maintenance operation, Figure 3. In this part, the results of the finite element simulation of both cases are presented by examining the mechanical behavior of the structure under low-velocity impact loadings. Indeed, the impact energy of the two scenarios studied is given in Table 4.

\section{$5.1 \quad$ Case 1}

The damage that appeared during the impact study in the first scenario is analyzed in this section. The impact was realized with low velocity $(V=4 \mathrm{~m} / \mathrm{s})$ on the trailing edge area of the nozzle. The Hashin criterion for fiber 


\begin{tabular}{|c|c|c|c|c|c|}
\hline \multirow[b]{2}{*}{ Configurations } & \multirow[b]{2}{*}{$\begin{array}{l}\text { Mass } \\
\text { (tons) }\end{array}$} & \multicolumn{2}{|l|}{ Case 1} & \multicolumn{2}{|l|}{ Case 2} \\
\hline & & $\begin{array}{l}\text { Velocity } \\
(\mathrm{m} / \mathrm{s})\end{array}$ & $\begin{array}{l}\text { Impact } \\
\text { energy } \\
(\mathbf{k J})\end{array}$ & $\begin{array}{l}\text { Velocity } \\
(\mathrm{m} / \mathrm{s})\end{array}$ & $\begin{array}{l}\text { Impact } \\
\text { energy } \\
(\mathrm{kJ})\end{array}$ \\
\hline CGG & 16.99 & 4 & 8 & 4 & 135.99 \\
\hline GCG & 16.99 & 4 & 8 & 4 & 135.99 \\
\hline GGC & 16.99 & 4 & 8 & 4 & 135.99 \\
\hline
\end{tabular}

TA B LE 4 The impact energy of the two scenarios studied
(A)

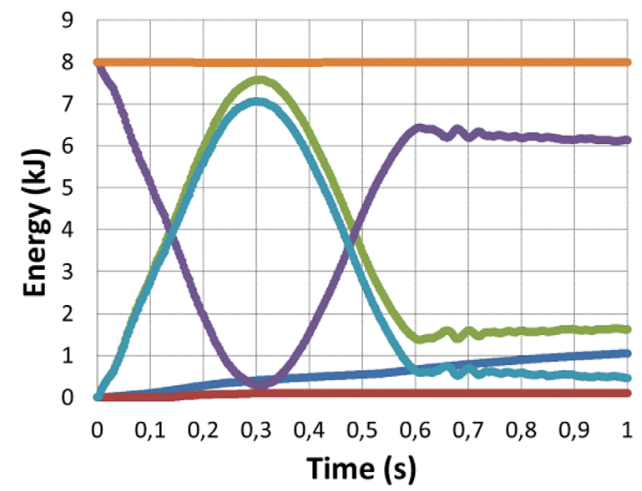

(B)

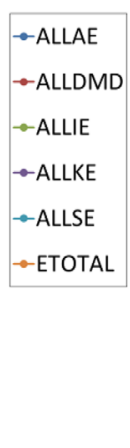

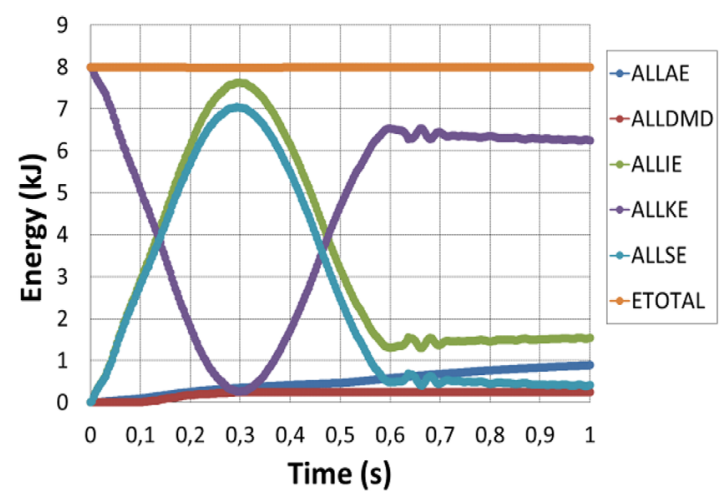

(C)

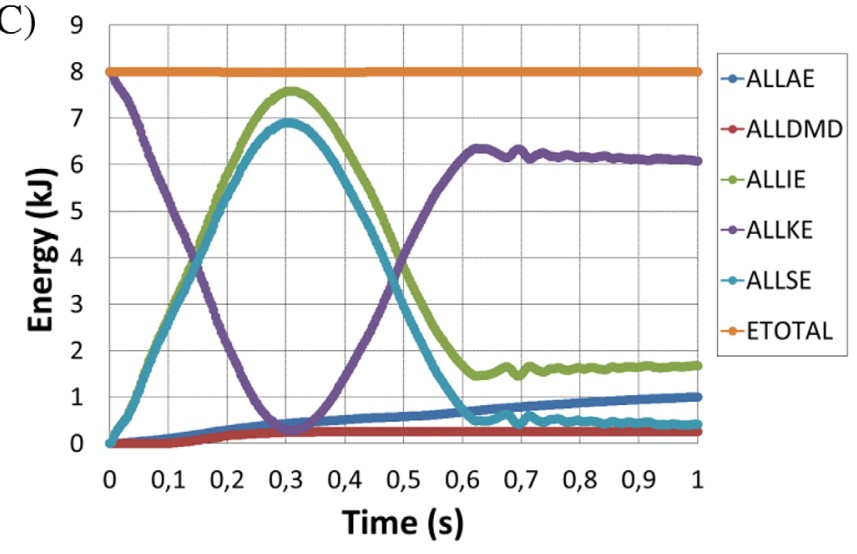

F I G U R E 6 Impact energy evolution during the study ( $m=1$ ton, $V=4 \mathrm{~m} / \mathrm{s}$ ) [Colour figure can be viewed at wileyonlinelibrary.com]

and matrix damage was adopted. ${ }^{32}$ The progression and formation of damage seen in materials are presented.

\subsection{1 | Energy conservation}

This section describes the energy variation of the CGG, GCG, and GGC configurations, Figure 6. The same trends are observed in all curves. The energy variation confirms the energy conservation theory of the system under investigation. Indeed, it appears that global energy remains constant during the whole duration of the calculation and is the expected energy impact. To validate the theory of energy conservation, the internal energy of the structure is equal to the energy of damage plus to the energy of deformation.

It is noted that: ALLAE, artificial energy; ALLDMD, damaging energy; ALLSE, strain energy; ALLKE, kinetic energy; ALLIE, internal energy; and ETOTAL, total energy.

Depending on the energy level, most studies on the impact of drop weight indicate three different modes of interaction between the impactor and the material. In the case of a very small quantity of energy absorbed by the composite, the projectile rebounds. Furthermore, if the majority of the energy is absorbed by different modes of damage, no rebound will be achieved. In the case of a high energy level, a perforation can be identified. ${ }^{37}$ 
Figure 7 shows energy curves for a drop-weight impact study for three materials where impactor rebound occurred. Throughout the impact study carried out, the rebound occurred for each hybrid composite examined. As

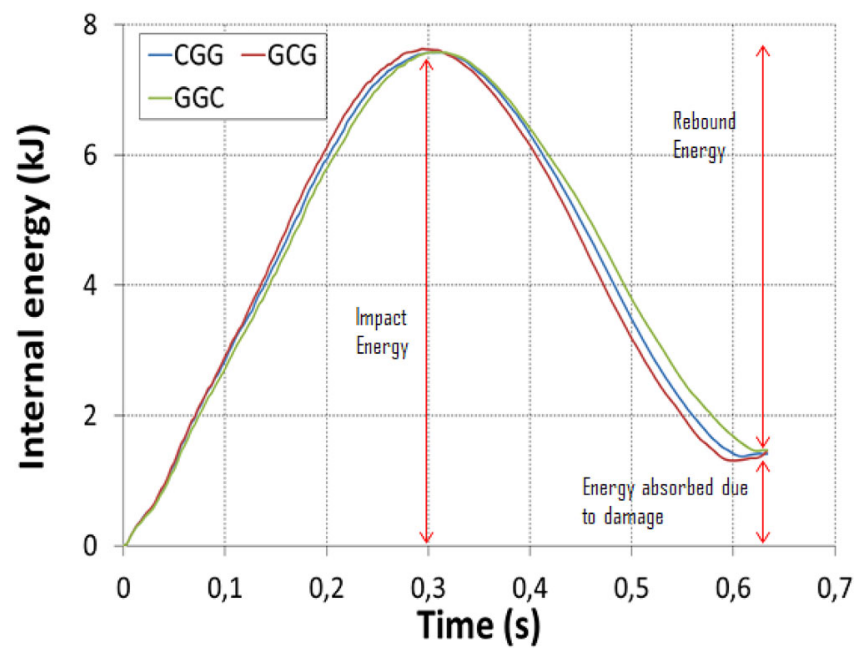

F I G U RE 7 Energy-time history of the three laminates at impact velocity $4 \mathrm{~m} / \mathrm{s}$ [Colour figure can be viewed at wileyonlinelibrary.com]

(A)

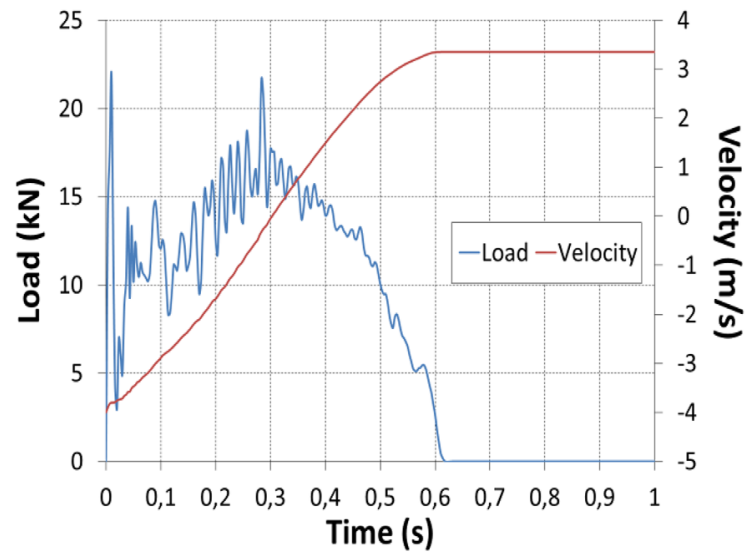

shown in Table 5, the hybrid composite GGC absorbs $1.67 \mathrm{~kJ}$ of energy, which is significantly higher than other types of configurations. The following section showed that a large quantity of damage has accumulated in this material. So, it is clear that this laminate will absorb more energy. On the other hand, CGG composite absorbs less energy due to its high rigidity.

\subsection{2 | Damaged structures}

Figure 8 shows the force and velocity-time graphs for different configurations of the stacking sequence of material.

T A B LE 5 Results of the low-speed impact study for the three materials

\begin{tabular}{llll} 
Materials & $\begin{array}{l}\text { Impact } \\
\text { energy } \\
(\mathbf{k J})\end{array}$ & $\begin{array}{l}\text { Absorbed } \\
\text { energy } \\
\mathbf{( k J )}\end{array}$ & $\begin{array}{l}\text { Rebound } \\
\text { energy } \\
(\mathbf{k J})\end{array}$ \\
\hline CGG & 8 & 1.54197 & 6.45803 \\
\hline GCG & 8 & 1.61999 & 6.38001 \\
\hline GGC & 8 & 1.67922 & 6.32078 \\
\hline
\end{tabular}

(B)

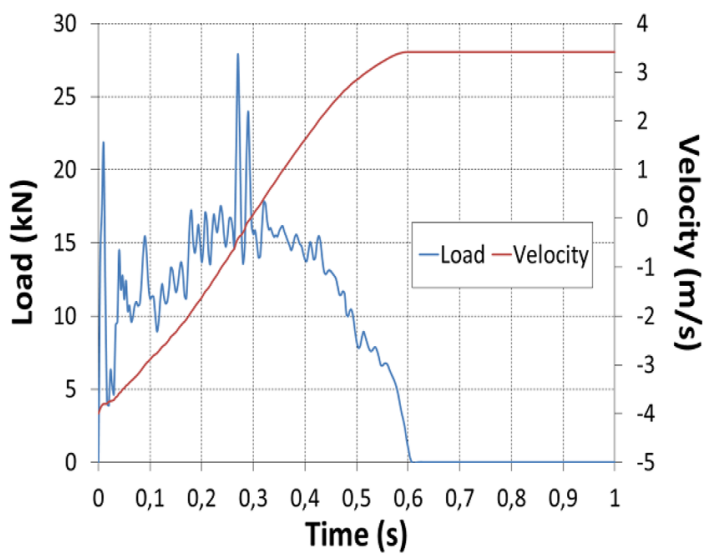

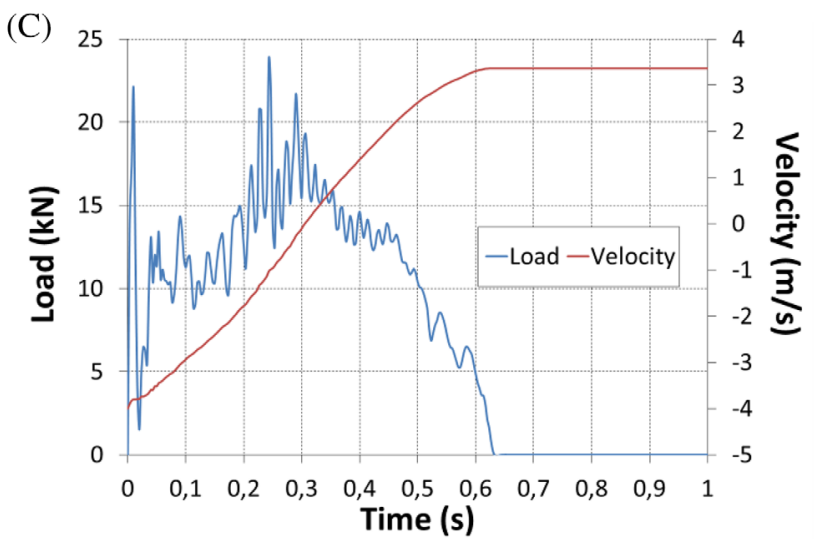

F I G U RE 8 Force- and velocity-time curves of different laminates [Colour figure can be viewed at wileyonlinelibrary.com] 
As illustrated in this figure, the force-time curves of the three configurations are quite similar. Indeed, the impactor force grows with the structure contact and attains its peak value, and then the contact force diminishes. During the impact, the trailing edge area sustained a vibration, which appeared as a fluctuation at the level of the force-time curve. The first peak occurs when the damage starts to form. The fluctuations that follow also reveal the formation of damage in the structure, which can be cracks in the matrix or fiber breakage.

The curves in Figure 8 also represent the variation of velocity during impact for the three configurations studied. This figure shows a progressive decrease in impactor speed until reaching zero, which corresponds to the initial phase of the elastic return. In this case, the impactor is probably hindered by the hybrid nozzle and thus loses a large part of its kinetic energy into deformation energy. As illustrated in Figure 8, the total duration of the impact is approximately 0.6 seconds. At this time, the contact force becomes nil, and the velocity begins to stabilize. So, there was a loss of contact between the impactor and the nozzle at that moment. On the other hand, the configuration GGC stabilizes rapidly compared to others. The principal cause behind this behavior is that the response to the impact of the nozzle changes as a function of the stacking sequence. Thus, it is evident that the force evolution after the first peak varies differently for the three materials under investigation.

As presented in Table 6, the greatest maximum contact force is $27.88 \mathrm{kN}$ and corresponds to the GCG

T A B L E 6 Maximum contact forces, displacement, and damage energy

\begin{tabular}{llll} 
Materials & $\begin{array}{l}\boldsymbol{F}_{\mathbf{m a x}} \\
(\mathbf{k N})\end{array}$ & $\begin{array}{l}\boldsymbol{U}_{\mathbf{m a x}} \\
(\mathbf{m m})\end{array}$ & $\begin{array}{l}\text { Max } \\
\text { damage } \\
\text { energy } \\
(\mathbf{J})\end{array}$ \\
\hline CGG & 219545 & 665634 & 107053 \\
GCG & 278878 & 654571 & 246906 \\
\hline GGC & 238035 & 682429 & 256482 \\
\hline
\end{tabular}

configuration, while the CGG configuration receives the lowest maximum contact force, which is $21.95 \mathrm{kN}$. Figure 9A compares the impact study responses in terms of impactor displacement for the three configurations. From an overall point of view, the simulation results show similar trends. In addition, the results presented in Table 6 indicate that the highest maximum displacement values are observed in the GGC configuration, while the lowest is found in the GCG and CGG configurations. In terms of damage energy, we can see from Figure 9B that the GGC configuration is the most damaged and CGG laminate is the last to be damaged. As Table 6 also shows, the CGG configuration obtains the lowest maximum damage energy. From the results, it is clear that this configuration has a higher stiffness response and therefore provides less impactor displacement. These results demonstrate that the material acts elastically when the carbon layer is situated on the internal surface, and two fibers layers of glass are situated on the external surface. So, the glass fibers protect the carbon layers.

The results of the different types of energy of the three materials studied indicate that the majority of the impact energy dissipates in the form of rigid and flexible movements of impact region (trailing edge), while a small part of the impact energy is absorbed in the nozzle as damage.

The low-impact energies lead to a sharp drop in resistance to implosion pressure. This decrease corresponds to the appearance of intralaminar cracks rather than delaminations. Impact damage favors a local implosion failure mechanism. Figure 10 shows the damaged areas of the tension matrix on the plies of CGG, GCG, and GGC laminates. The absence of the damaged zones was observed in the tension fibers, which is the reason that only illustrative cartography of the damaged areas of the tension matrix has been presented. Indeed, on the CGG laminate, the damage is little, while on the GGC laminate, a slight increase was observed because the external surface of the GGC stratified is covered with the carbon fiber layer that is exposed to high contact load and very easily damaged on contact. Indeed, the constraints occurring in these
(A)

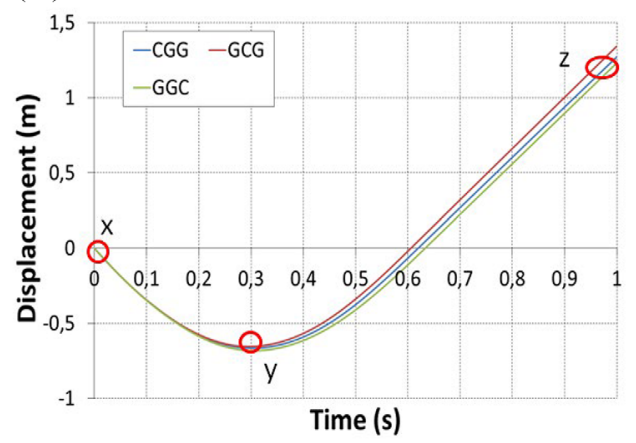

(B)

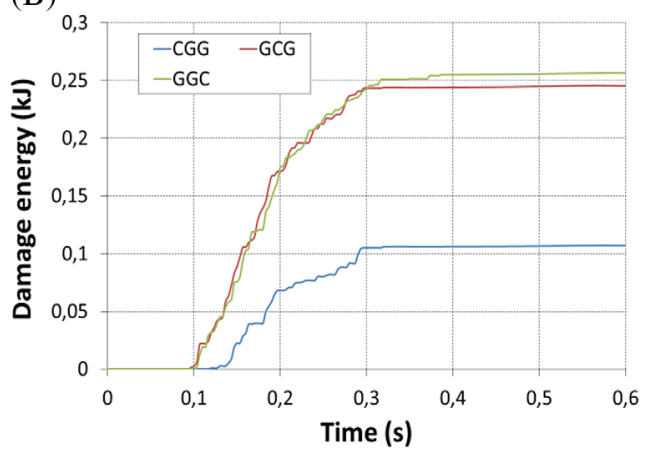

FI G URE 9 The damage energy and displacement curves of the three configurations [Colour figure can be viewed at wileyonlinelibrary.com] 
(A)
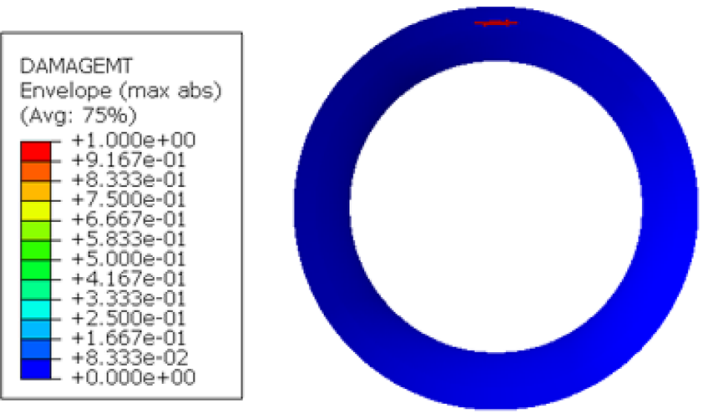

Y

$\frac{1}{2} \rightarrow x$ Step: Step

83137: Step Time $=1.000$

Primary var: DAMAGEMT

(B)

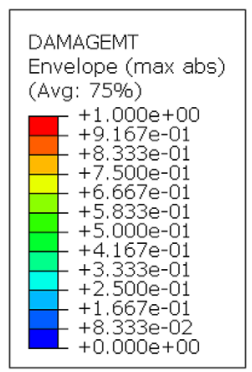

$\mathrm{Y}$

$\underset{\mathbb{t}}{\mathbb{4}} \mathrm{x}$ Step: Step-1

Increment 83137: Step Time $=1.000$ Primary Var: DAMAGEMT

(C)
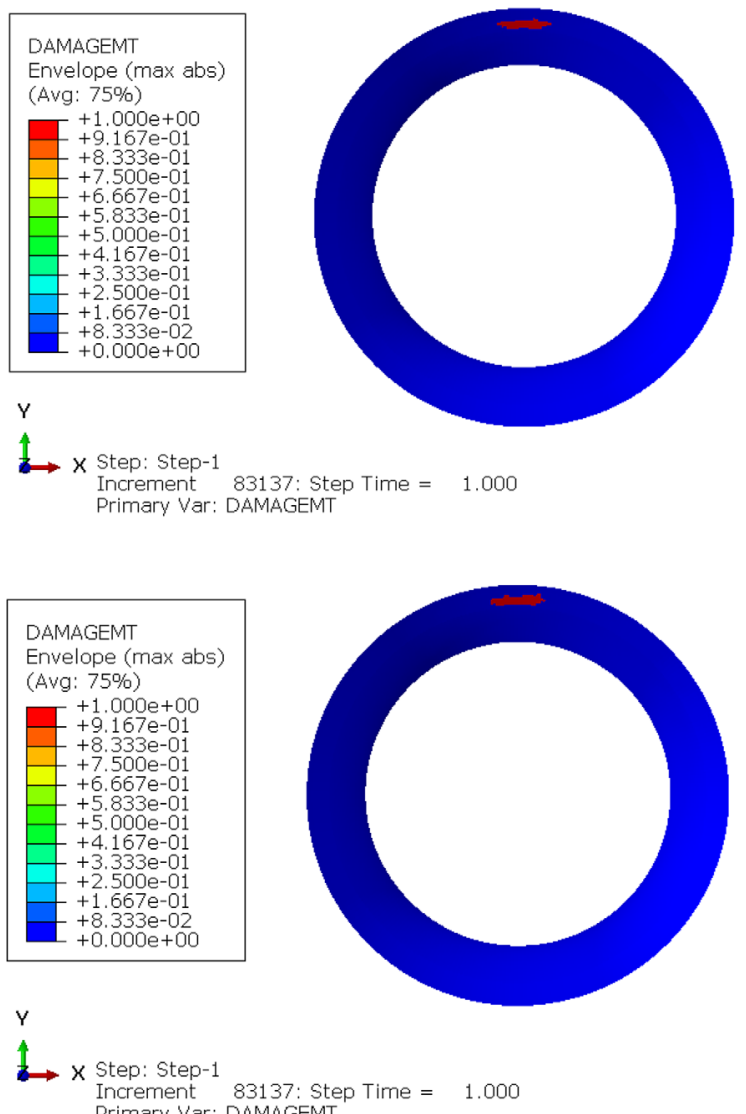
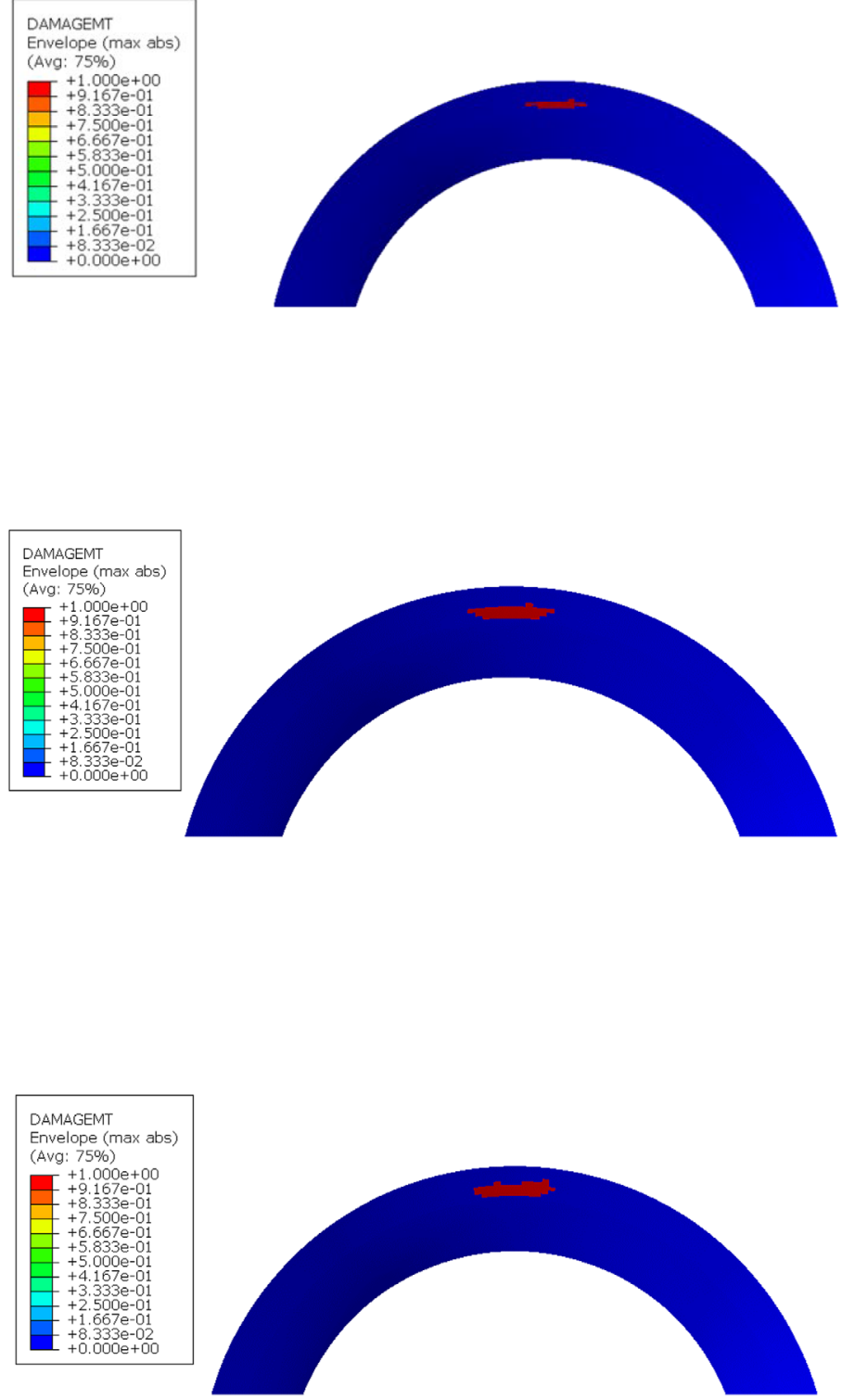

F I G U RE 10 Representation of laminate damage zones (DAMAGEMT) [Colour figure can be viewed at wileyonlinelibrary.com]

regions could generate the creation of a zone where adjacent plies are delaminated. The mechanical performance of the nozzle is susceptible to be affected by the appearance of this mode of damage and its development.

\subsection{Case 2}

\subsection{1 | Effect of the staking sequence}

In this impact scenario, the nozzle with its trailing edge impacts a plane surface during the maintenance operation, so the impact energy is expected to be high given that the mass of the nozzle is of the order of several tons. In the previous case, the damage that appeared at the nozzle was not very large. In this second case, the results of the damage assessment are presented for $V=4 \mathrm{~m} / \mathrm{s}$ and $m=16.99$ tons, which results in the impact energy of more than $135 \mathrm{~kJ}$. Figure 11 shows a comparative curve of the contact forces with the damage energy generated in the nozzle for the three laminates studied. It can be observed in the three laminates that the damage energy tracks the contact force history curve, with maximum damage energy accumulated where there is the highest contact force. Indeed, at the point where ALLDMD appears, the contact force curve (at the first peak) displays an oscillating nature with a 
(A)

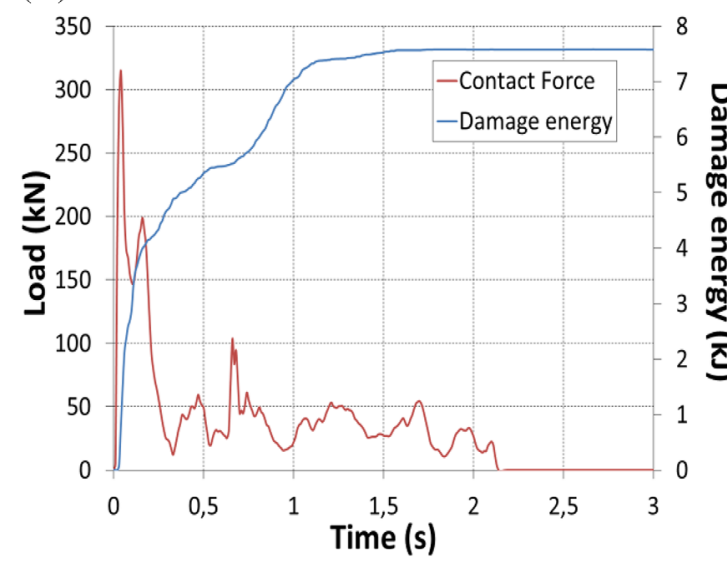

(B)

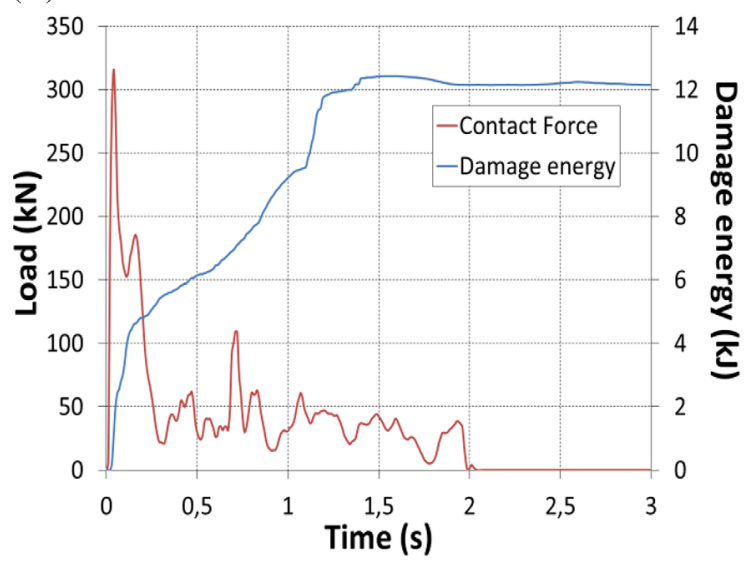

(C)

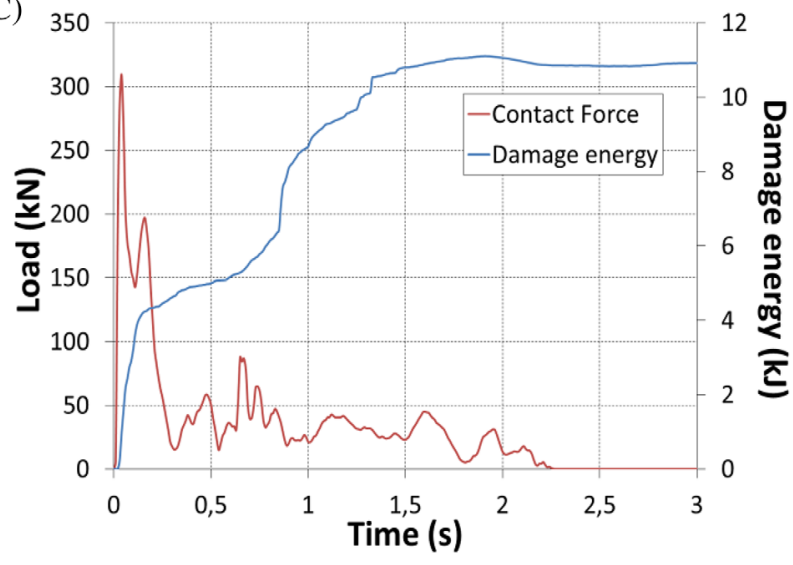

F I G U RE 11 Contact force with damage energy (ALLDMD) of the three laminates [Colour figure can be viewed at wileyonlinelibrary.com]

T A B L E 7 Maximum values of displacement, contact force, and damage energy

\begin{tabular}{|c|c|c|}
\hline Materials & $\begin{array}{l}F_{\max } \\
(\mathbf{k N})\end{array}$ & $\begin{array}{l}\text { Max } \\
\text { damage } \\
\text { energy } \\
(\mathrm{kJ})\end{array}$ \\
\hline CGG & 315.129 & 7.58462 \\
\hline GCG & 315.909 & 12.4301 \\
\hline GGC & 309.609 & 11.1076 \\
\hline
\end{tabular}

varying slope. This demonstrates a change in material rigidity and damage growth in the nozzle. However, at this energy level of $135 \mathrm{~kJ}$, the smallest values of maximum contact force are found in the GGC configuration, while the highest value is observed in the GCG configuration, as shown in Table 7.

Regarding damage energy, the most damaged material is the one with a GCG configuration, while the CGG material is the most resistant, Table 7. As already seen in the first case, the material becomes more resistant to damage formation, especially when the carbon layer is situated on the internal surface and two fiber layers of glass are situated on the external surface.
These changes in the curve of contact force and damage energy correspond to a physical phenomenon. In fact, when the incident energy is greater than $8 \mathrm{~kJ}$, the damage mechanism changes, and there is a growth of intralayer cracks and delamination. However, this rise in the density of the intralaminar cracks occurs after all the interfaces have separated.

A considerable difference in nozzle movement after impact for the three materials can also be observed from Figure 12. For the GCG and GGC configuration, velocity is dominant at the midpoints of the nozzle (Figures 12B,C), and thus a large deformation of the structure after impact is detected. However, for the impact of the nozzle in the CGG laminate, the velocity and motion of the nozzle are not sufficiently dominant as compared to the other laminates.

\subsection{2 | Damage in tension}

Figure 13 presents significantly the effect of the impact on the behavior of the layers stratified. The damage is very large and concentrated at the trailing edge of the nozzle for all three configurations. It can be deduced 
(A)
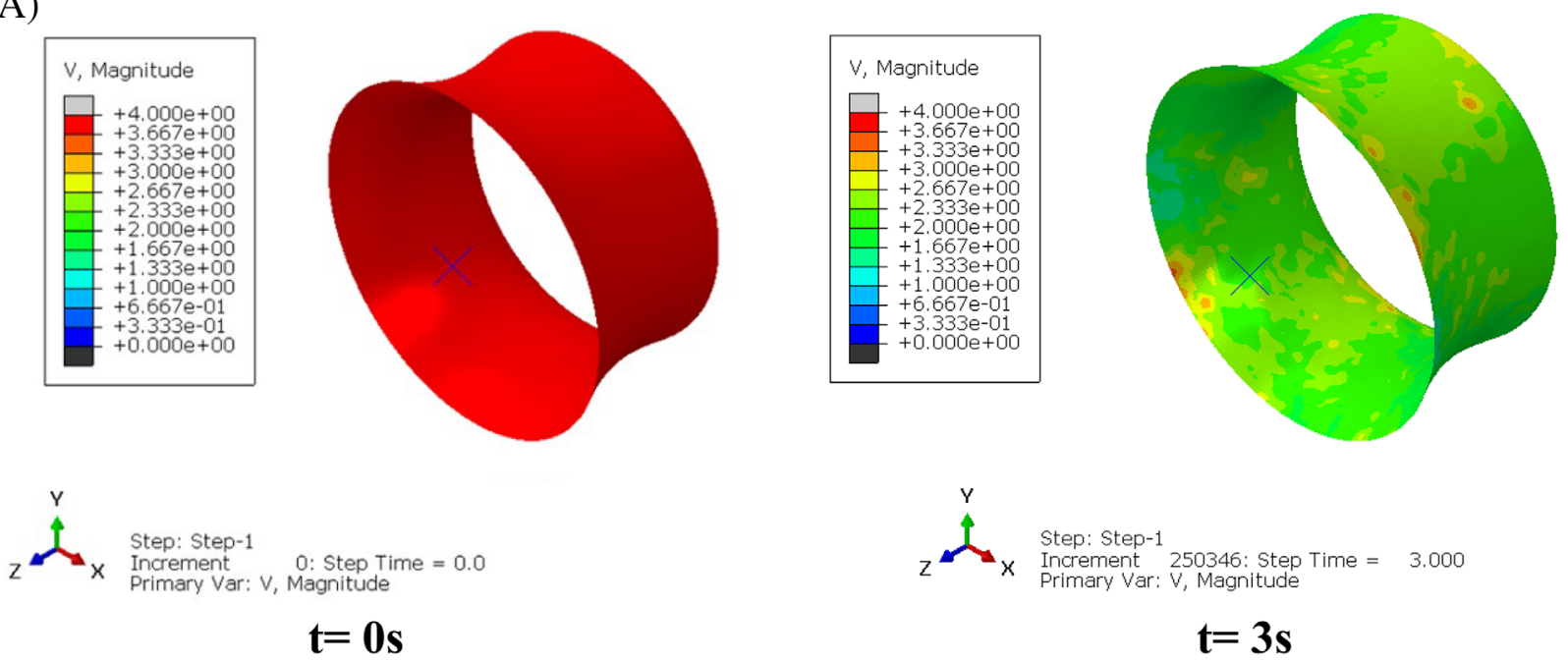

$$
\mathbf{t}=\mathbf{3 s}
$$

(B)
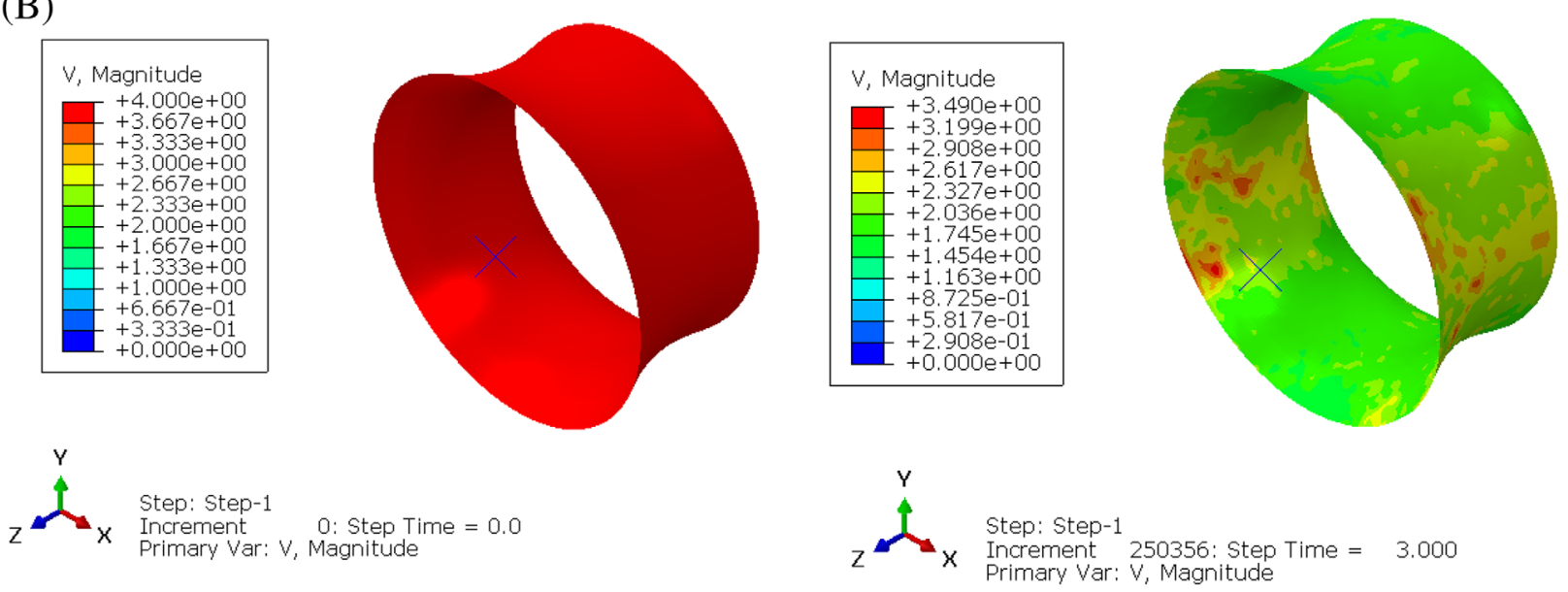

$$
\mathbf{t}=\mathbf{0 s}
$$

$$
\mathbf{t}=\mathbf{3 s}
$$

(C)
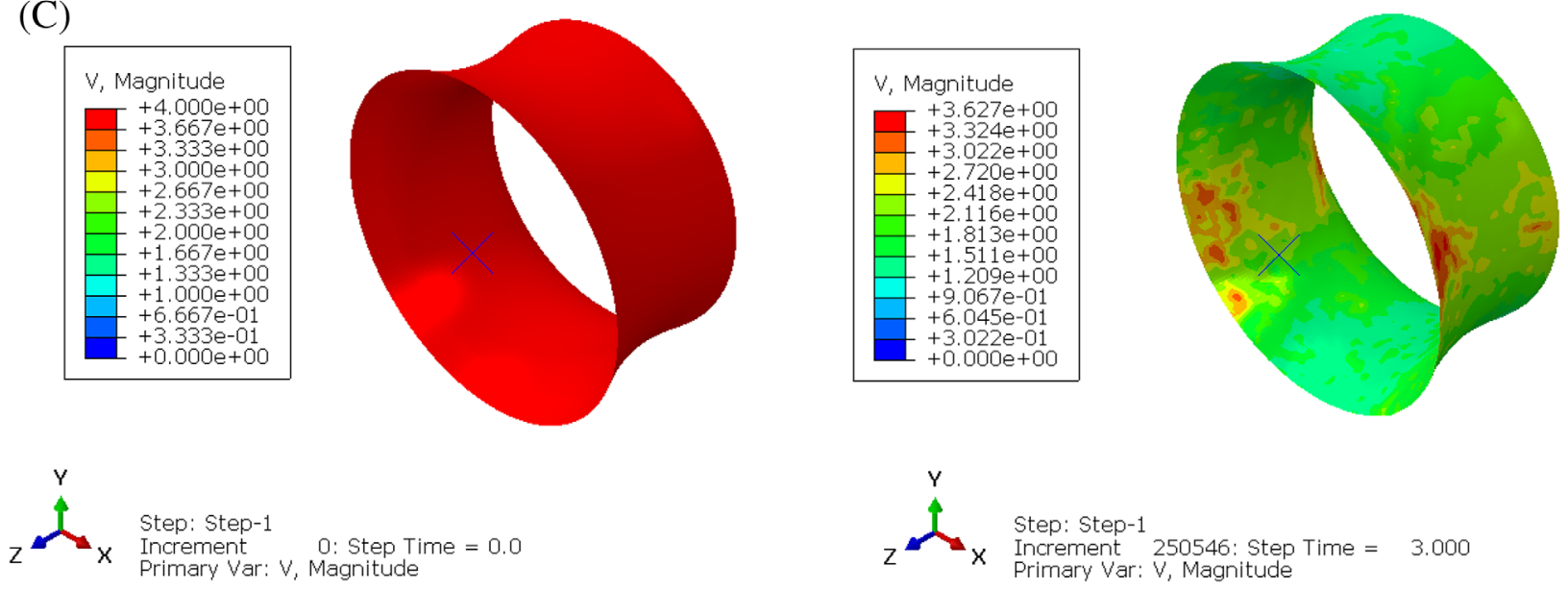

$$
\mathbf{t}=\mathbf{0 s}
$$

\section{$\mathbf{t}=\mathbf{3 s}$}

F I G U RE 12 Velocity profile after the impact of the three structures [Colour figure can be viewed at wileyonlinelibrary.com]

from this figure that a perforation of the structure has taken place in the impact zone given that the impact energy is very high since the mass of the nozzle is of the order of several tons. Indeed, from a comparative point of view, deformations and damage to the tension matrix of the GCG and GGC configurations are more important. On the other hand, no damaged regions on the tension fibers were observed for all three configurations. 
(A)
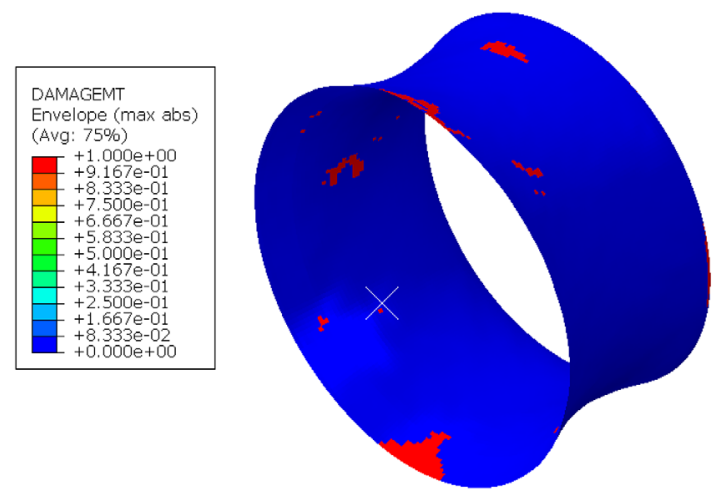

${ }_{z}$

Step: Step-1

Increment 250346: Step Time $=3.000$

Deformed Var: $U$ Deformation Scale Factor: $+1.000 e+00$

(B)
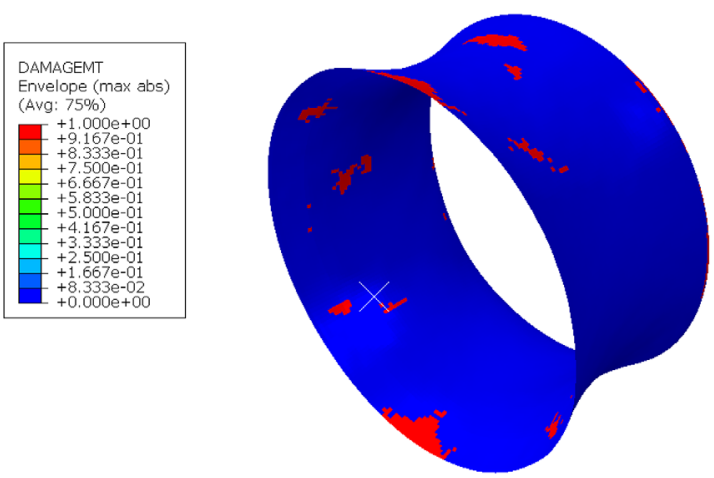

Step: Step-1
Increment 250356: Step Time $=3.000$
Primary Var: DAMAGEMT

Deformed Yar: U Deformation Scale Factor: $+1,000 e+00$

(C)
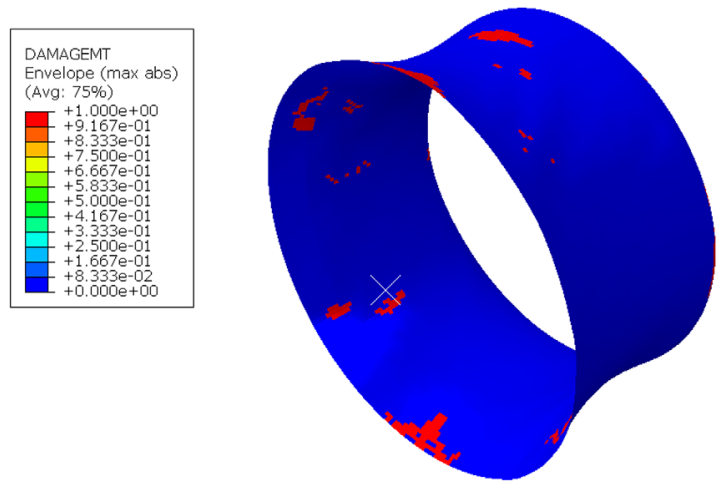

$\mathrm{L}_{\mathrm{x}}$

Step: Step-1

Increment 250546: Step Time $=3.000$

Deformed Var: $U$ Deformation Scale Factor: +1 . n00e +00
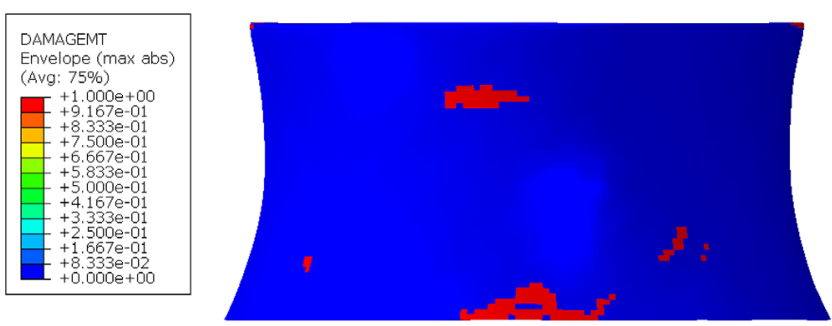

Step: Step-1
Increment 250346: Step Time $=3.000$
$\begin{aligned} & \text { Primary Var: DAMAGEMT } \\ & \text { Deformed Var: } U \text { Deformation Scale Factor: }+1.000 e+00\end{aligned}$
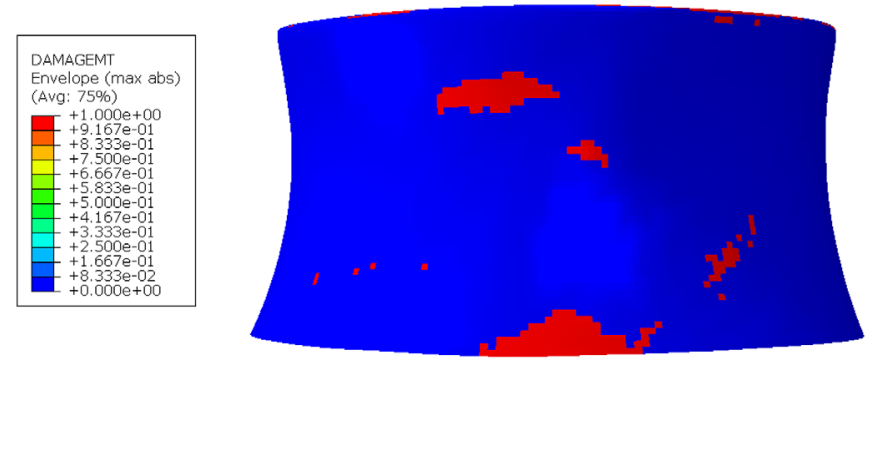

$\longrightarrow x \begin{aligned} & \text { Step: Step-1 } \\ & \text { Increment } 250356 \text { : Step Time }=3.000 \\ & \text { Primary Var: DAMAGEMT } \\ & \text { Deformed Var: }\end{aligned}$

Deformed Var: $U$ Deformation Scale Factor: $+1.000 e+00$
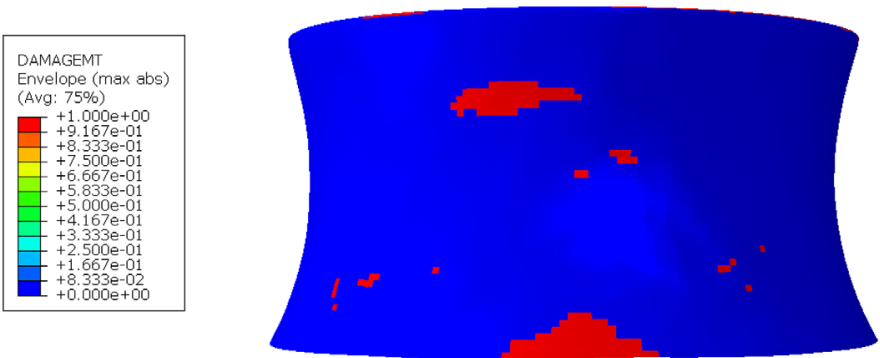

$\longrightarrow x$ Step: Step-1 1 Increment $250546:$ Step Time $=3.000$

Deformed Var: $U$ Deformation Scale Factor: $+1.000 e+00$

F I G U RE 13 Representation of the damage zones of the laminates under study (DAMAGEMT) [Colour figure can be viewed at wileyonlinelibrary.com]

\subsection{3 | Damage in compression}

The results obtained in the previous sections confirmed that the CGG configuration was resistant to shock, while the GCG and GGC configurations were the most damaged. To better visualize these results, Figures 14 and 15 show a comparative damage status of the fibers and matrix in compression of these three configurations. The damage status DAMAGEFC is less than 1 for the CGG laminate, which indicates the absence of damage in this failure mode, Figure 14A. On the other hand, the level of damage DAMAGEFC and DAMAGEMC observed on the 
GCG and GGC laminates is greater than 1, which signifies the existence of damage in these failure modes. Indeed, the size of the areas that concentrate damage on
GCG and GGC laminates is larger than the size of the CGG, Figures 14 and 15. This finding completes the energy results discussed previously.
(A)
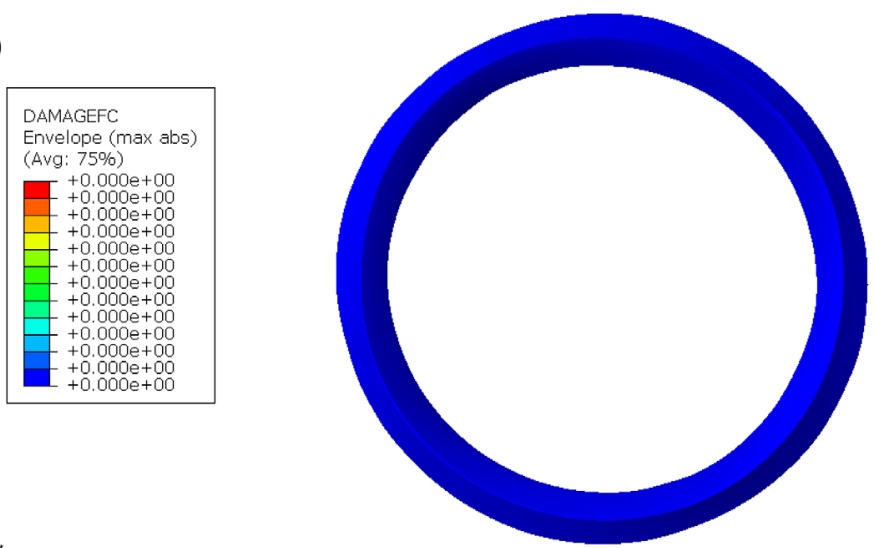

Step: Step-1

Increment 250346: Step Time $=3.000$

Deformed Var: $U$ Deformation Scale Factor; $+1.000 e+00$

(B)
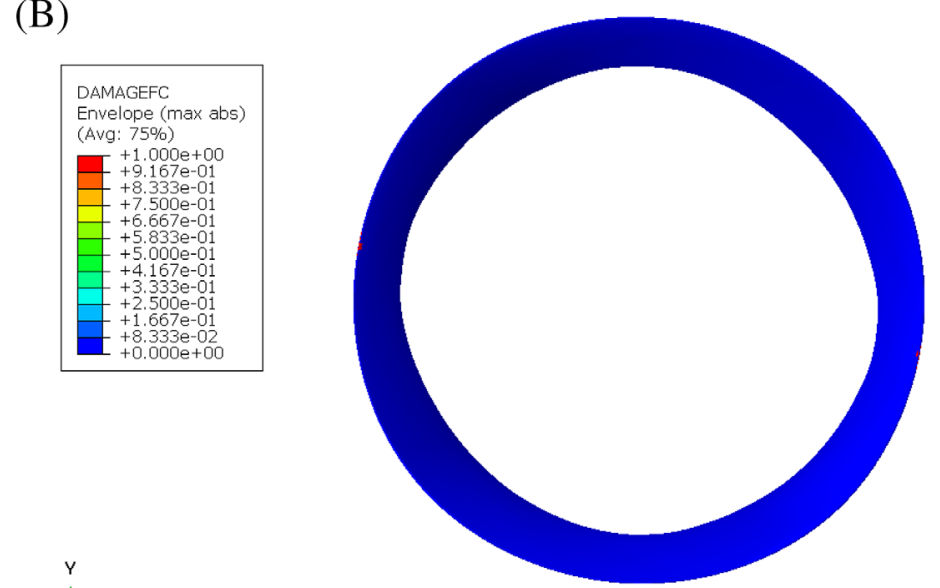

$x \leftarrow 4$

Step: Step-1

Increment 250356: Step Time $=3.000$

Deformed Var: $U$ Deformation Scale Factor: $+1.000 e+00$

(C)
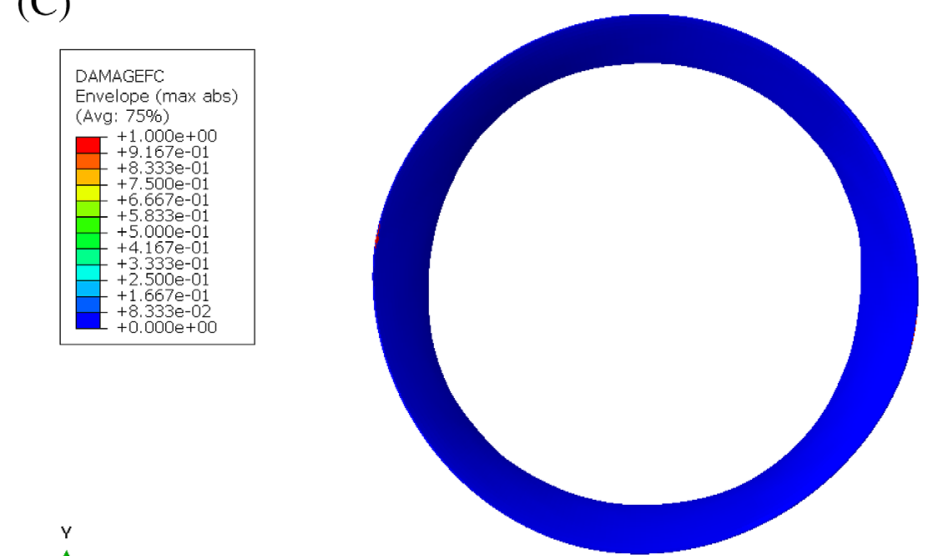

$x+4$

Step: Step-1
Increment

Increment 250546: Step Time $=3.000$

Deformed Var: $U$ Deformation Scale Factor: $+1.000 e+00$

F I G U RE 14 Failure criterion of the fiber in compression (DAMAGEFC) [Colour figure can be viewed at wileyonlinelibrary.com]
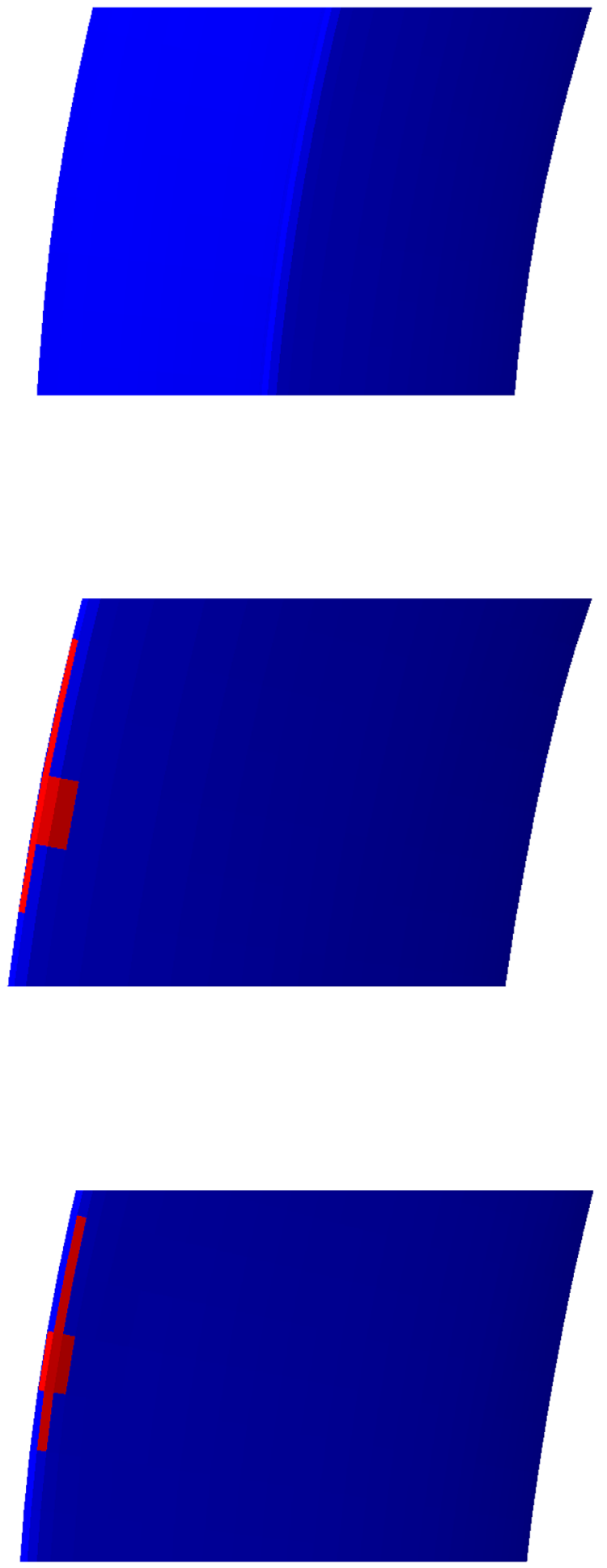
(A)
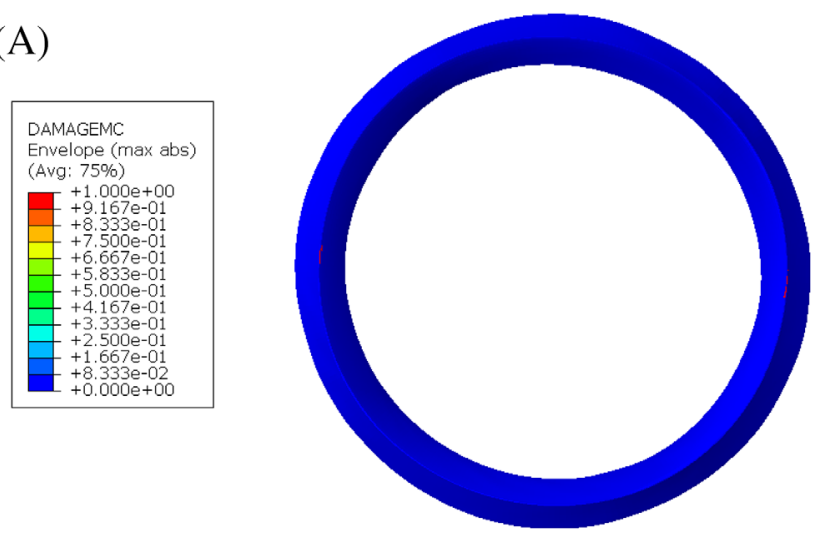

$x \longleftarrow$

Step: Step-1

Increment 250346: Step Time $=3.000$

Deformed Var: $U$ Deformation Scale Factor: +1.000 e+00

(B)

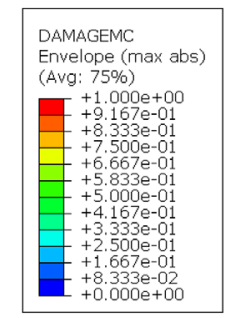

$x+6$

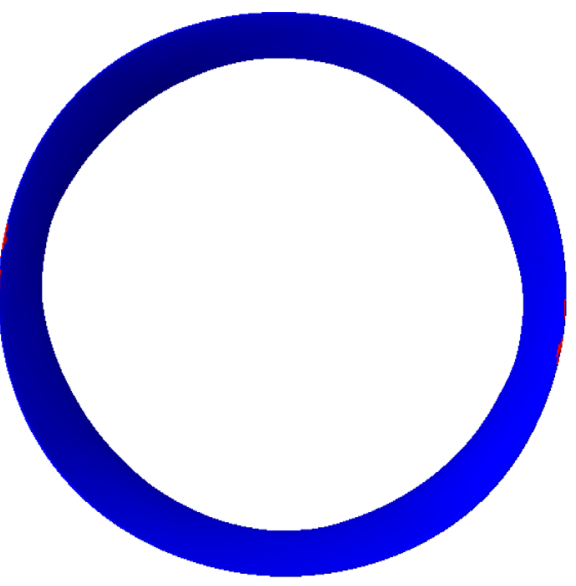

Step: Step-1
Increment 250356: Step Time $=3.000$
Primary Var: DAMAGEMC

Deformed Var: U Deformation Scale Factor: $+1,000 e+00$

(C)

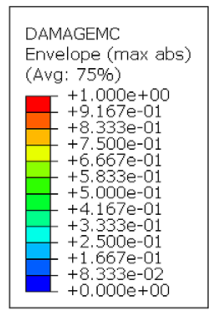

$\times \stackrel{4}{\rightarrow}$

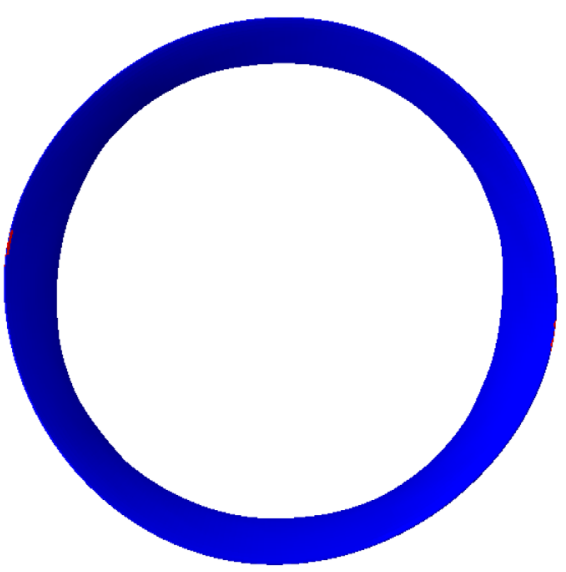

Step: Step-1
Increment 250546: Step Time $=3.000$

Deformed Var: $U$ Deformation Scale Factor: $+1.000 \mathrm{e}+00$
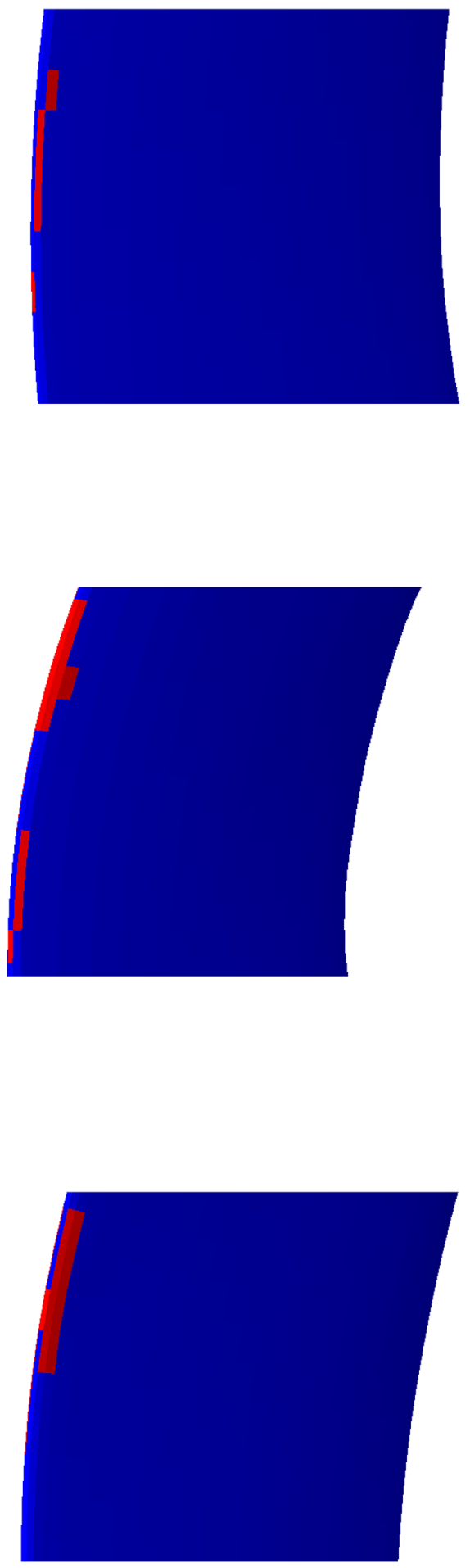


\section{6 | CONCLUSION}

This study analyzed comprehensively the response of a hybrid composite nozzle under impact during a maintenance operation. It was indicated that operations are risky in the open sea if the vessel itself is not large enough to remain stable against waves during transhipment operations. This can lead to complex damage modes in the nozzle, capable of harming their structural integrity. In this context, a numerical simulation of progressive damage based on the Hashin criterion was conducted to predict failure modes. Two impact scenarios were studied and three types of hybrid laminates were adopted in order to identify the best stacking sequence, allowing the formation of damage on the composite hybrid nozzle subjected to a low-velocity impact at the trailing edge area. The energy conservation of the nozzle was verified to validate the numerical model. In addition, the results of the forcetime curves of the three configurations were quite close to each other. Indeed, during the impact, the trailing edge area was damaged, which appeared as fluctuations at the level of the force-time curve. The results of the two impact scenarios demonstrated that the stacking sequence significantly influences the formation of damage. However, the results showed that the identified damage modes were large in GGC laminate. In contrast, the damage concentrated in the CGG configuration was low compared to the other laminates. Based on these results, we concluded that the carbon layer is perfectly protected by glass layers and gives the most resistance for damage formation. In the first impact scenario, most of the impact energy was dissipated as rebound energy and only about $3.1 \%$ was dissipated as damage energy. Concerning the second case, 9.25\% was dissipated as damage energy, which resulted in a perforation of the nozzle with the plane surface at the contact region. For the designer, research on the behavior of a tidal current turbine under shock is of great interest. Even small damage may have a significant influence on structure sustainability.

\section{CONFLICT OF INTEREST}

The authors declare that they have no known competing financial interests or personal relationships that could have appeared to influence the work reported in this paper.

\section{DATA AVAILABILITY STATEMENT}

The data that support the findings of this study are available from the corresponding author upon reasonable request.

\section{ORCID}

Houda Laaouidi (iD) https://orcid.org/0000-0001-7442-0292

\section{REFERENCES}

1. Nachtane M, Tarfaoui M, Goda I, Rouway M. A review on the technologies, design considerations and numerical models of tidal current turbines. Renew Energy. 2020;157:1274-1288.

2. Zhang J, Moreau L, Machmoum M, Guillerm P-E. State of the art in tidal current energy extracting technologies, International Conference on Green Energy ICGE 2014; 2014. p. 1-7.

3. Nachtane M, Tarfaoui M, El Moumen A, Saifaoui D. Numerical investigation of damage progressive in composite tidal turbine for renewable marine energy, International Renewable and Sustainable Energy Conference (IRSEC); 2016. pp 559-563.

4. Uihlein A, Magagna D. Wave and tidal current energy-a review of the current state of research beyond technology. Renew Sustain Energy Rev. 2016;58:1070-1081.

5. Mey Gen, Tidal Projects. SIMEC atlantis energy (n.d). Available from https://simecatlantis.com/projects/meygen/. Accessed March 20, 2020.

6. phy.org. Pioneering turbine sets new benchmark for tidal renewable energy (n.d). Available from https://phys.org/news/ 2018-10-turbine-benchmark-tidal-renewable-energy.html. Accessed March 20, 2020.

7. Nachtane M, Tarfaoui M, Ait Mohammed M, Saifaoui D, El Moumen A. Effects of environmental exposure on the mechanical properties of composite tidal current turbine. Renew Energy. 2020;156:1132-1145.

8. Brunetti A, Armenio V, Roman F. Large eddy simulation of a marine turbine in a stable stratified flow condition. $J$ Ocean Eng Mar Energy. 2019;5:1-19.

9. Velasco ML, Correa E, París F. Interaction between fibres in the transverse damage in composites. Eng Fract Mech. 2020; 239:107273.

10. Andraju LB, Raju G. Continuum and cohesive zone damage models to study intra/inter-laminar failure of curved composite laminates under four-point bending. Compos Struct. 2020;253: 112768.

11. Xi L, Ma D, liu H, et al. Assessment of failure criteria and damage evolution methods for composite laminates under lowvelocity impact. Compos Struct. 2019;207:727-739.

12. Mohammad RHA, Mohammad RF, Daneshkhah E. Damage and residual bending strength in glass-polyester molded grating composite panels after low-velocity impact. Compos Struct. 2019.227:111290-111301.

13. Zhao L, Shan M, Hong H, Qi D, Zhang J, Hu N. A residual strain model for progressive fatigue damage analysis of composite structures. Compos Struct. 2017;169:69-78.

14. Jia W, Wen W, Fang L. Low-velocity impact and post-impact biaxial residual strength tests and simulations of composite laminates. Compos Struct. 2020;235:111758.

15. Fagan EM. Ciaran R. Kennedy, Sean B. Leen, \& Jamie Goggins, damage mechanics based design methodology for tidal current turbine composite blades. Renew Energy. 2016;97:358-372.

16. Tual N, Carrere N, Davies P, Bonnemains T, Lolive E. Characterization of sea water ageing effects on mechanical properties of carbon/epoxy composites for tidal turbine blades. Compos $A$ Appl Sci Manuf. 2015;78:380-389.

17. Sujon MAS, Habib MA, Abedin MZ. Experimental investigation of the mechanical and water absorption properties on fiber stacking sequence and orientation of jute/carbon epoxy hybrid composites. J Mater Res Technol. 2020;9:10970-10981. 
18. Wu L, Wang W, Jiang Q, Lin J-H, Tang Y. Illustrating hybrid effect and damage evolution of carbon/aramid braided composite under low-velocity impact. Compos Struct. 2020;245:112372.

19. Santhanam V, Dhanaraj R, Chandrasekaran M, Venkateshwaran N, Baskar S. Experimental investigation on the mechanical properties of woven hybrid fiber reinforced epoxy composite. Materials Today: Proceedings. 2020. http://dx. doi.org/10.1016/j.matpr.2020.07.444.

20. Mahmoud B, Manseri L, Rogani A, et al. Experimental and numerical study of the damage mechanisms in hybrid unidirectional/woven composites under impact loading. Compos Struct. 2019;209:606-615.

21. Sun G, Tong S, Chen D, Gong Z, Li Q. Mechanical properties of hybrid composites reinforced by carbon and basalt fibers. Int J Mech Sci. 2018;148:636-651.

22. Aranno TM, Mia S, Ullah Khan MS, Hasan MAM, Shams Supto N, Shaid Sujon A. Fabrication, experimental investigation of jute fiber reinforced epoxy composites and hybrid composites. IOP Conference Series: Materials Science and Engineering; 2019. pp. 1-6.

23. Sujon AS, Mehfuz N. Experimental and numerical investigation on the tensile and water absorption behavior of jute/carbon reinforced epoxy, international journal of mechanical. Eng Technol. 2020;11(2):130-140.

24. Gemi L. Investigation of the effect of stacking sequence on low velocity impact response and damage formation in hybrid composite pipes under internal pressure, a comparative study. Compos Part B Eng. 2018;153:217-232.

25. Guinard S, Allix O, Guédra-Degeorges D, Vinet A. A 3D damage analysis of low velocity impacts on laminated composites. Compos Sci Technol. 2002;62:585-589.

26. Chen P, Shen Z, Xiong J, Yang S, Fu S, Ye L. Failure Mechananism of laminated composites subjected to static Identation. Compos Struct. 2006;75:489-495.

27. Nachtane M, Tarfaoui M, Saifaoui D, El Moumen A, Hassoon $\mathrm{OH}$, Benyahia H. Evaluation of durability of composite materials applied to renewable marine energy: case of ducted tidal turbine. Energy Rep. 2018;4:31-40.

28. Matzenmiller A, Lubliner J, Taylor RL. A constitutive model for anisotropic damage in fiber-composites. Mech Mater. 1995; 20:125-152.
29. Nachtane M, Tarfaoui M, El Moumen A, Saifaoui D. Damage prediction of horizontal axis marine current turbines under hydrodynamic, hydrostatic and impacts loads. Compos Struct. 2017;170:146-157.

30. Tarfaoui M, Shah OR, Nachtane M. Design and optimization of composite offshore wind turbine blades. J Energy Res Technol. 2018;5:141-150.

31. Mohammed MA, Tarfaoui M. Study of composites ducts for optimal design of an horizontal axis tidal turbine [Thesis]. 2017.

32. Gning PB, Tarfaoui M, Collombet F, Riou L, Davies P. Damage development in thick composite tubes under impact loading and influence on implosion pressure: experimental observations. Compos Part B Eng. 2005;36:306-318.

33. Tarfaoui M, Gning PB, Hamitouche L. Dynamic response and damage modeling of glass/epoxy tubular structures: numerical investigation. Compos A Appl Sci Manuf. 2008;39(1):1-12.

34. Tarfaoui M, Gning PB, Davies P, Collombet F. Scale and size effects on dynamic response and damage of glass/epoxy tubular structures. J Compos Mater. 2007;41(5):547-558.

35. Gning PB, Tarfaoui M, Collombet F, Davies P. Prediction of damage in composite cylinders after impact. J Compos Mater. 2005;39(10):917-928.

36. Tarfaoui M, Gning PB, Collombet F. Residual strength of damaged glass/epoxy tubular structures. J Compos Mater. 2007; 41(18):2165-2182.

37. Sevkat E, Liaw B, Delale F, Raju BB. Drop-weight impact of plain-woven hybrid glass-graphite/toughened epoxy composites. Compos A Appl Sci Manuf. 2009;40:1090-1110.

How to cite this article: Laaouidi $\mathrm{H}$, Tarfaoui $\mathrm{M}$, Nachtane M, Trihi M. Energy absorption characteristics in hybrid composite materials for marine applications under impact loading: Case of tidal current turbine. Int J Energy Res. 2020;1-18. https://doi.org/10.1002/er.6210 